تنمية اتجاه الطالبات نحو قيمة تحمل المسؤولية

$$
\text { منتهى إبراهيم بن محارب }
$$

محاضر بقسم الدراسات الاجتماعية كلية الآداب جامعة الملك سعود إبرد 
تشكل القيم الاجتماعية مرجعيةً ثقافيةً لتوجيه سلوكيات الأفراد نحو المرغوب وغير المرغوب؛ لاسيما قيمة تحمل المسؤولية التي تعتبر مِن القيم المهمة في الحياة الشخصية والاجتماعية.

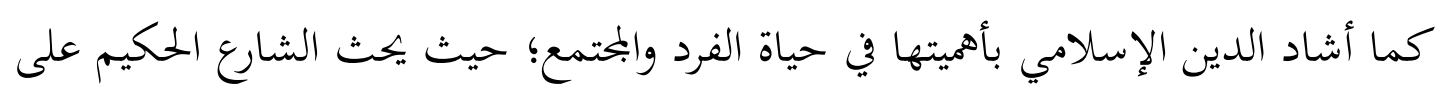
الالتزام بالمسؤولية بين أفراد البمتمع؛ لما لها مِن أثر بالغ في الحياه الحياة الاجتماعية.

الاتجاهات:

تعتبر دراسة الابحاهات مِن أهم الموضوعات الاجتماعية؛ حيث تخضع كل الظواهر

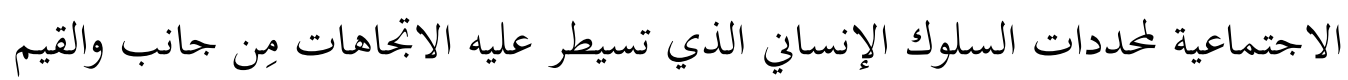

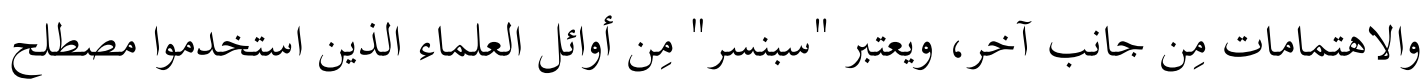

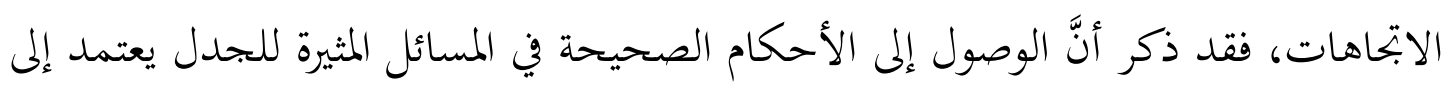

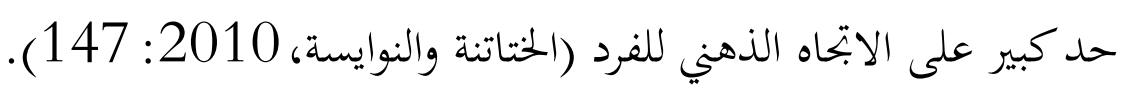

\section{مفهوم الاتجاهات:}

لا يوجد اتفاق حول مفهوم الاتجاه إذ إنَّ كل مستخدم يضع له تعريف يختلف في بعض الآنا

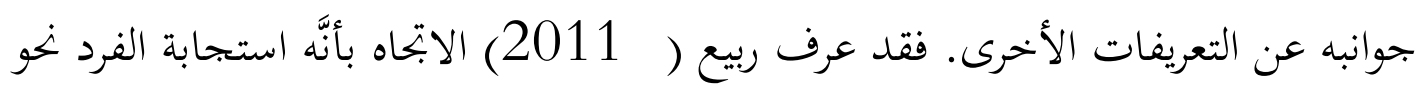

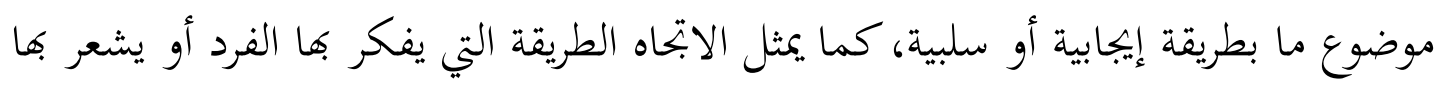

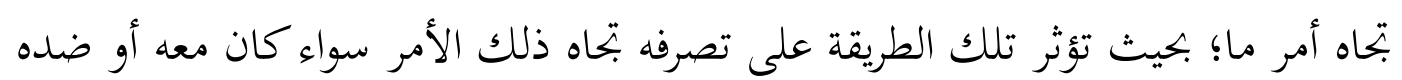
(ربيع، 2011: 265).

ويمكن تلخيص الاتجاهات في أَََّّا استعدادات للقيام بنشاط ما بطريقة معينة، فهي تتعامل مع بحموعة مِن العمليات التي تشتمل على الحوافز والرغبات والاحتياجات والميول والآمال

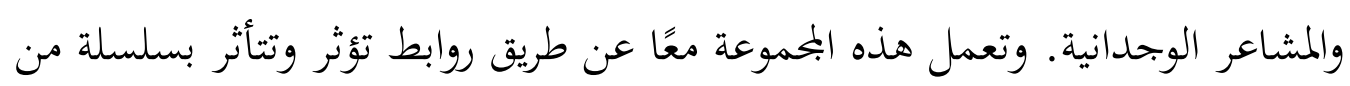

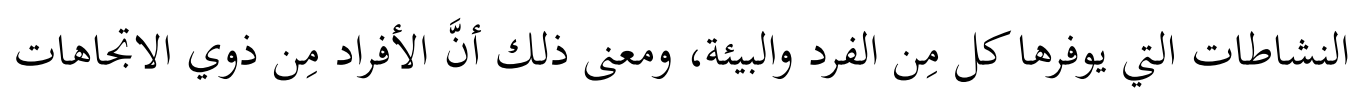

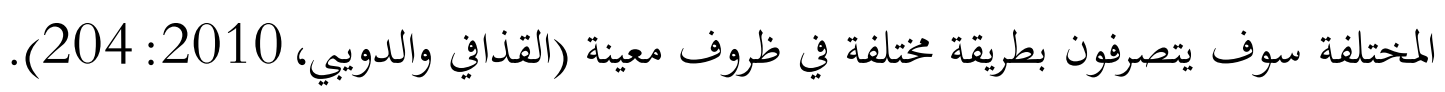




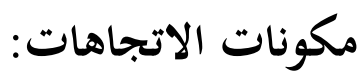

للابتحاه ثلاثة مكونات تتمثل فيما يلي:

أولاً: المكون العاطفي أو الوجداني:

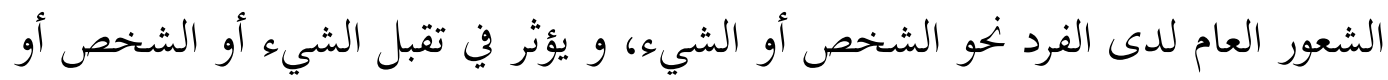

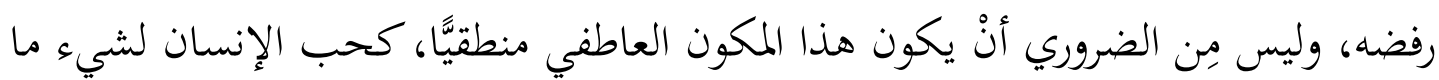
دون سبب مقنع.

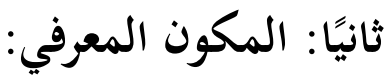
وهو المعلومات والمعارف التي تنطوي عليها وجهة نظر الشخص صاحب الاتحاه نحو الشيء

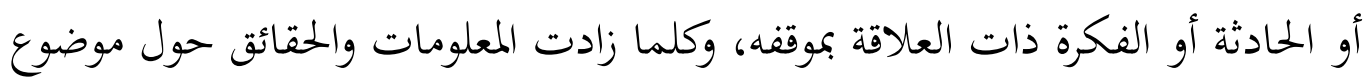

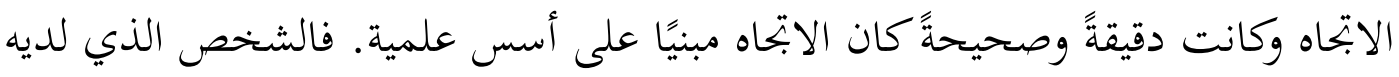

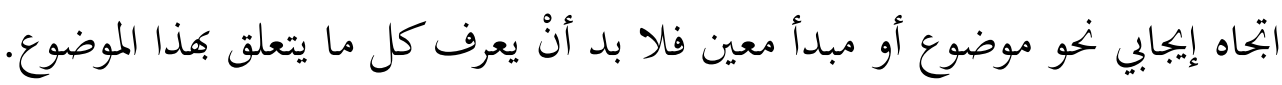
ثالثًا: المكون السلوكي أو الإدراكي:

وهو الفعل الذي يقوم به الفرد والذي يشير إلى ابتحاه نحو شيء معين أو شخص أو فكر

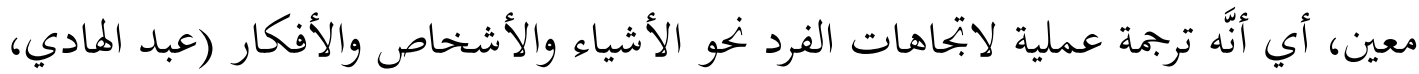

. (184:2011

\section{العوامل المؤثرة في تكوين الاتجاهات:} هناك عدة عوامل تؤثر في تكوين الاتحاه، وهي: 1 القبول النقدي للمعايير الاجتماعية عن طريق الإيحاء: يعتبر الإيحاء مِن أكثر العوامل

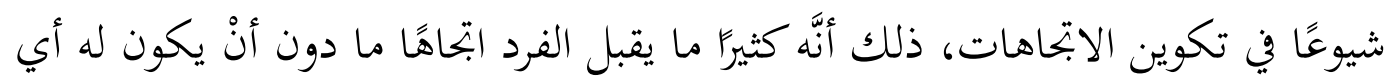
اتصال مباشر بالأشياء أو الموضوعات المتصلة بهذا الاتحاه، فالاتحاه أو تكوين رأي ما، تحدده المعايير الاجتماعية العامة التي يمتصها الأبناء مِن آبائهم دون نقد أو تفكير، فتصبح جزعًا مِن تقاليدهم وحضارتم يصعب عليهم التخلص مِنه، ويلعب الإيحاء دورًا مهمَّا في تكوين الاتحاهات فهو أحد الوسائل التي يكتسب بها الفرد المعايير السائدة في المحتمع دينيةً كانت

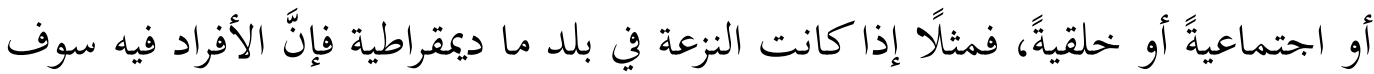


2 / تعميم الخبرات: فالإنسان دائمًا يستعين بخبراته الماضية ويعمل على ربطها بالحياة

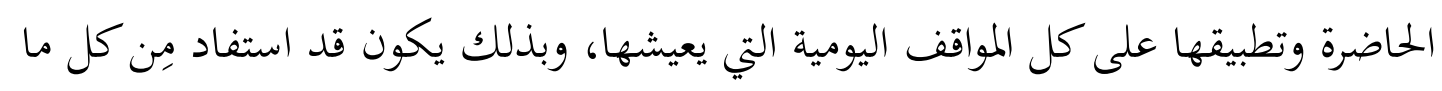
تعلمه مِن خبرات في ماضيه، ويعمل على تعميمه في كافة نواحي حياته.

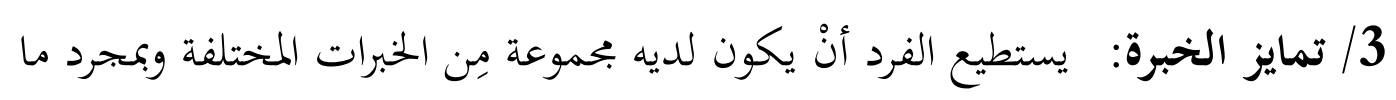

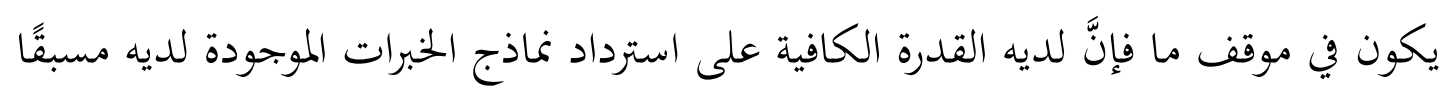
وتطبيق المناسب منها.

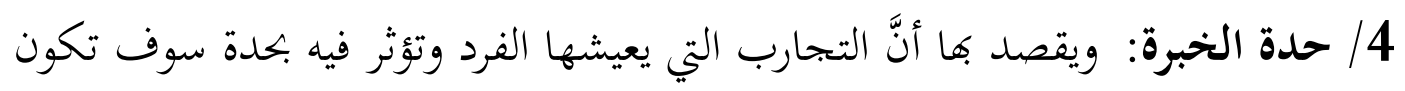

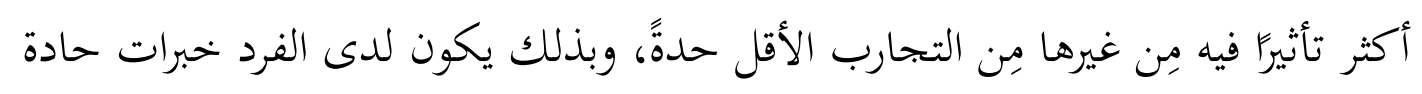
تساعد في تكوين ابتحاهات الفرد نحو القضايا (الختاتنة والنوايسة، 2010:

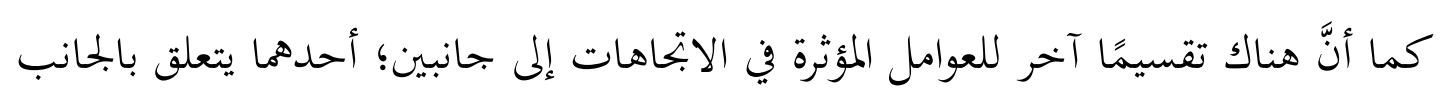

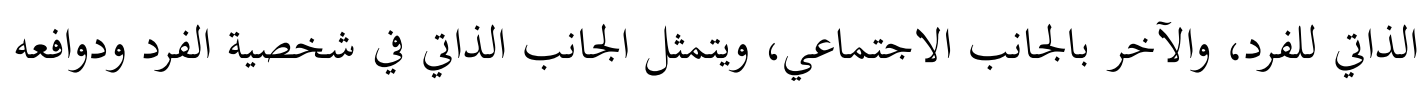

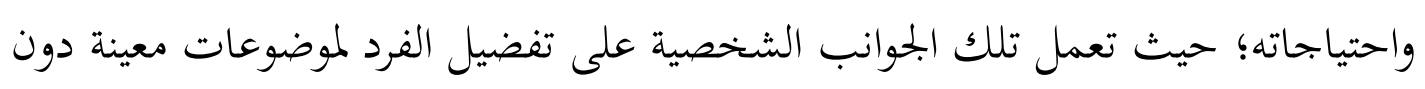

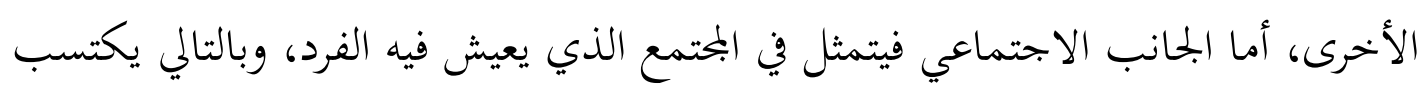

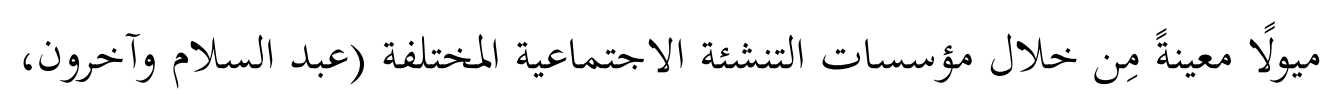
165: 2002

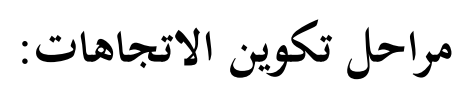
يمر تكوين الاتجاهات لدى الفرد بثلاث مراحل أساسية؛ حيث يبدأ تكوين الاتجاه بمرحلة

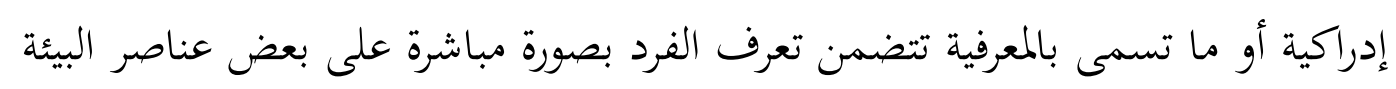

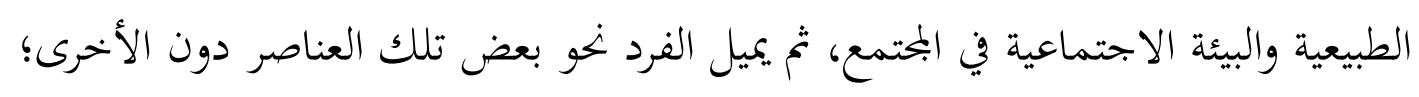

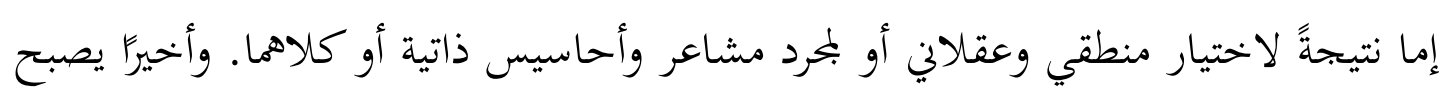

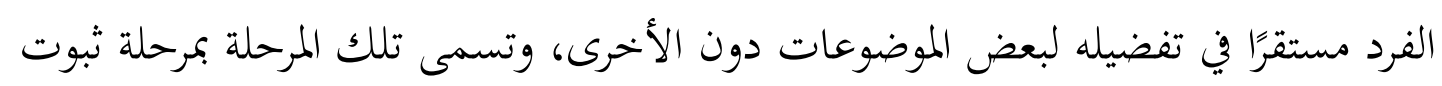

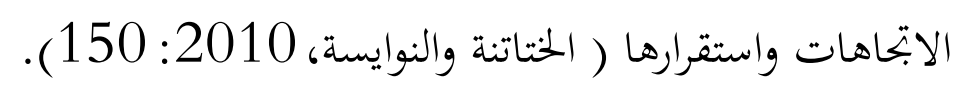

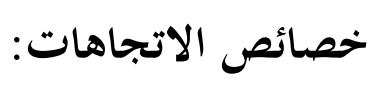
يرى عبد اللا أنَّ هناك بحموعةً مِن الخحائص التي تتسم بها الاتحاهات، وهي كالآتي: 
1/ يكتسب الفرد الاتجاهات مِن خلال احتكاكه بالبيئة التي يعيش فيها، وذلك ما يوضح أنَّ الاتحاهات ليست موروثة وإنما متعلمة.

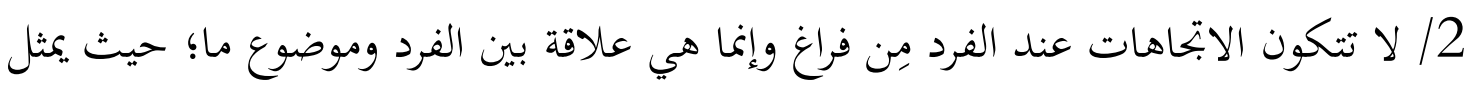
الابتحاه معنى يربط الإنسان بشيء معين أو قضية؛ نتيجة مروره بخبره ترتبط بالموضوع.

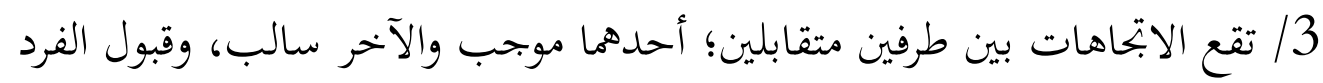
للموضوع يعني أنَّ يتجه نخو الإيجابية، أما رفضه يتجه به إلى السلبية. 4/ يمكن قياس اتجاهات الفرد نخو موضوع ما، كما يمكن تعديل ابتحاتهاته أو تغييرها.

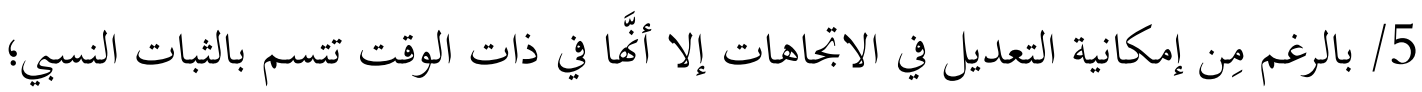

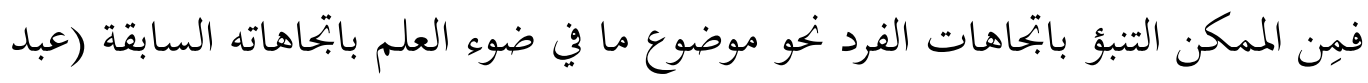

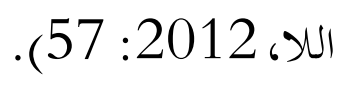

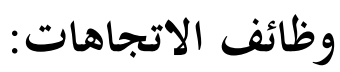

مِن خلال الاطلاع على المراجع التي تناولت وظائف الاتحاهات يمكن تحديد أهم وظائف

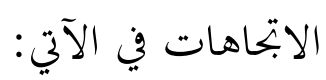

1/ الوظيفة المعرفية: تكمن في حاجة الإنسان للتعامل مع بناء ثابت ومنظم وذي معنى في

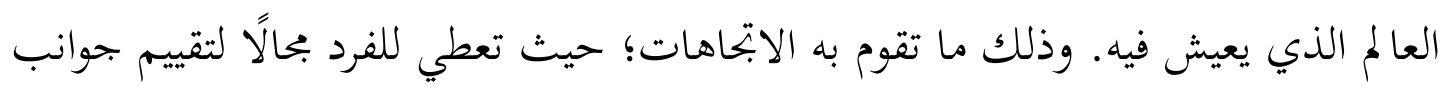

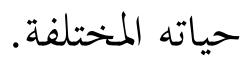

2/ الوظيفة التعبيرية وتحقيق الذات: تعمل الابتاهات على ترجمة القيم والمعتقدات التي يعتنقها الفرد؛ فتتضح هوية الفرد ويستطيع التعبير عن ذاته وعما يقبله أو يرفضه.

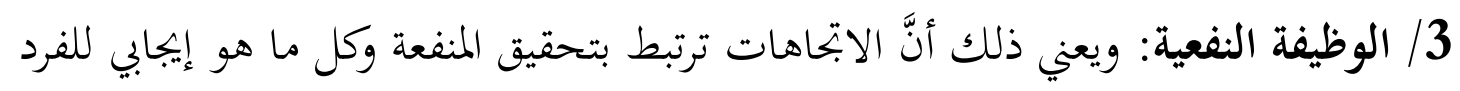

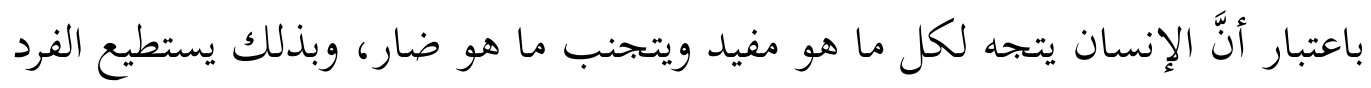

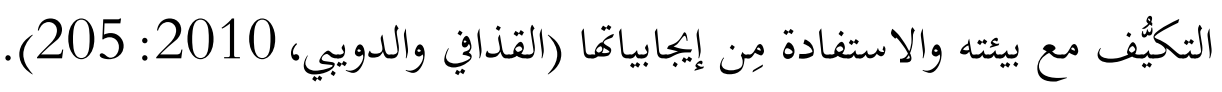

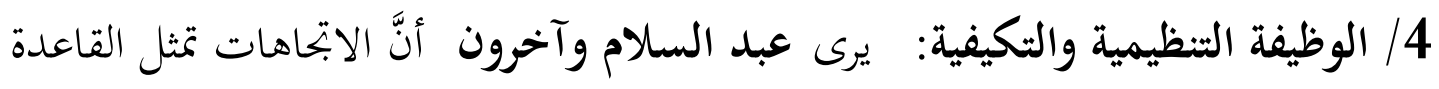

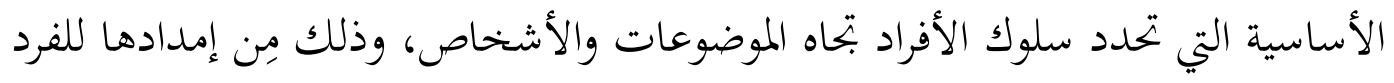

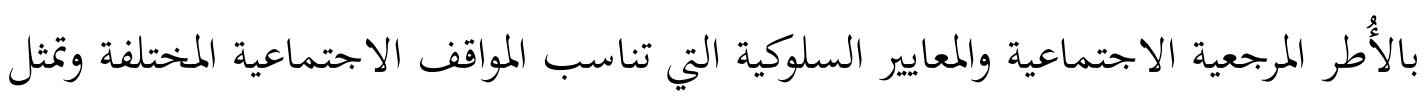

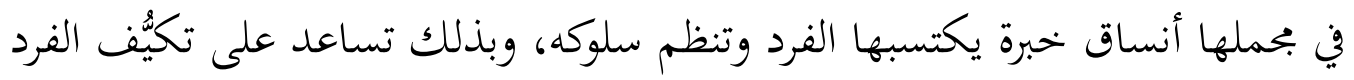




$$
\begin{aligned}
& \text { بدرجة عالية مع ذاته ومع الآخرين ومع البيئة التي يعيش فيها بشكل عام (عبد السلام }
\end{aligned}
$$

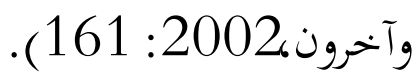

كما يضيف جابر عدة وظائف للاتجاهات، وهي كالآتي: 1/ تحدد سلوك الفرد نحو موضوع ما؛ حيث توجه سلوك الفرد بطريقة معينة متناسبة مع الاتحاهات التي يعتنقها الفرد.

2/ تستخدم في العلاج النفسي؛ حيث يحاول المعالجون تغيير نظرة الفرد إلى نفسه وإلى لئل الآخرين والمجتمع ككل مِن خلال الاتجاهات.

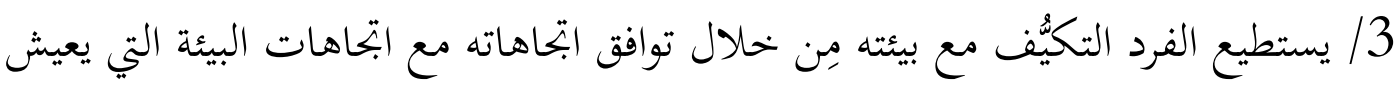
فيها، وبذلك يمصل الفرد على الدعم مِن أعضاء الجماعة.

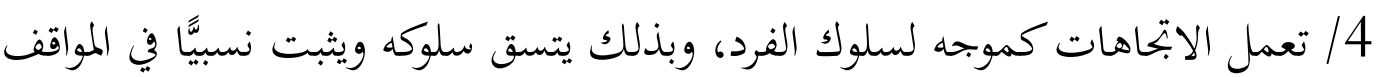

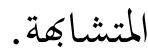

5/ تعطي للفرد فرصة التعبير عن نفسه، وذلك مِن خلال استجابته للموضوعات التي يرغبها

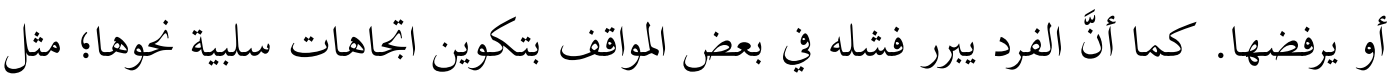
الطالب الذي يفشل في تعليمه قد يبرر ذلك بسوء نظام التعليم (بني جابر، 2011: .$(269$

\section{طرق التعبير عن الاتجاهات:}

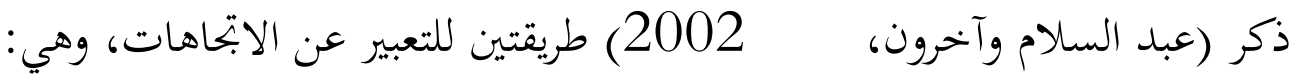
1/ الطرق اللفظية: وهي طريقة يعبر بها الفرد مِن خلالها عن ابتحاهاته باستخدام الألفاظ واللغة، وذلك مِن خلال التعبير الصريح أو الضمني الذي يتلفظ به الفرد؛ سواء في أحاديثه مع الآخرين أو في إجابته عن الأسئلة التي توجه إليه.

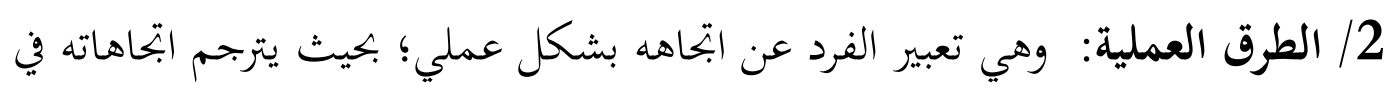

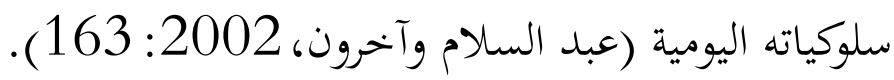
العوامل المساعدة في تغيير الاتجاهات: يوجد عدة عوامل تساعد على تغيير الاتجاهات لدى الفرد، وهي كما يلي: 
1/ تغيير الإطار المرجعي للفرد: ويقصد بذلك تغيير العادات والتقاليد والأعراف والمفاهيم

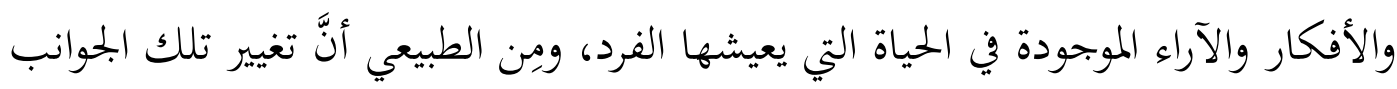

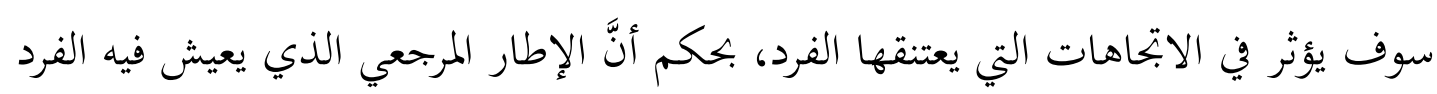
يؤثر في اعتناقه لاتجاهات معينة دون غيرها.

2/ تغيير الجماعات المرجعية التي ينتمي إليها الفرد: ويقصد بذلك تغيير الجماعات

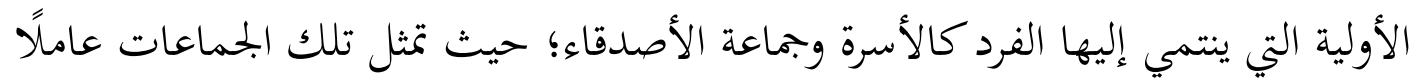

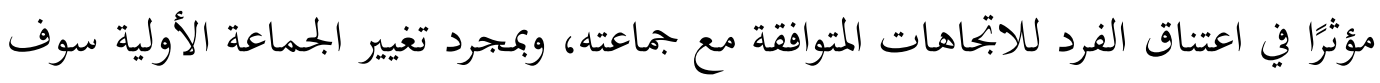
تتغير ابتاهات الفرد. 3/ وسائل الإعلام: تساهم وسائل الإعلام في تغيير ابتحاهات المتلقي مِن خلال ما تبثه مِن

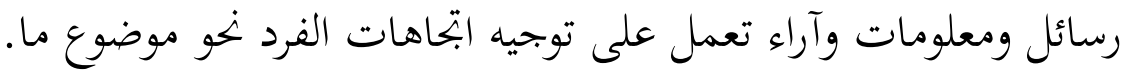

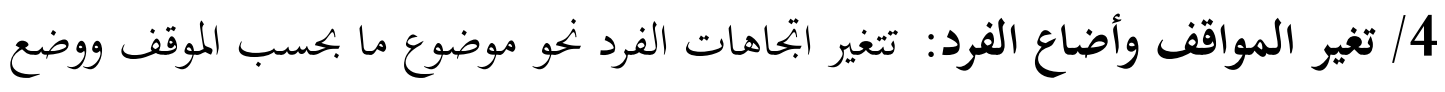

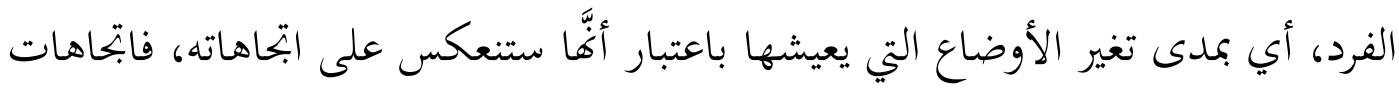
الشباب قد تتغير بعد أنْ يتقدم بهم العمر، وهكذا.

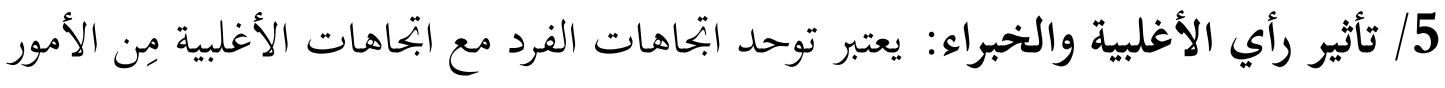

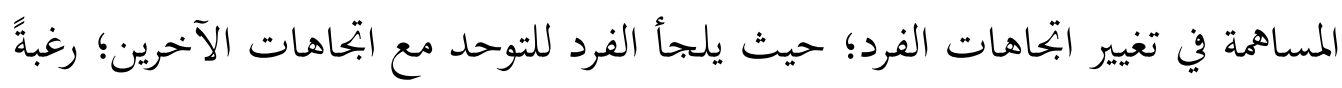

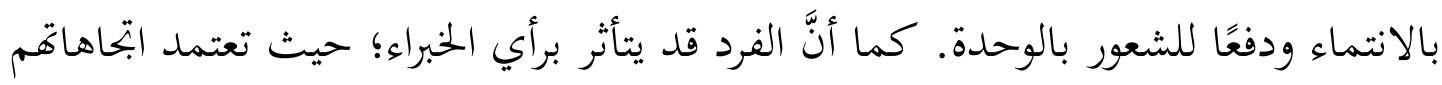

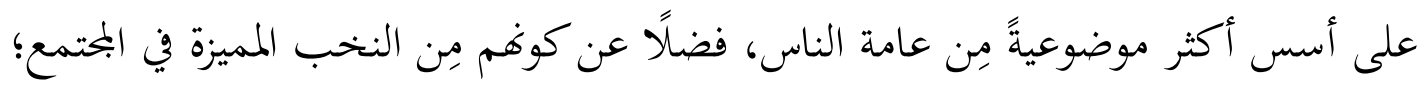

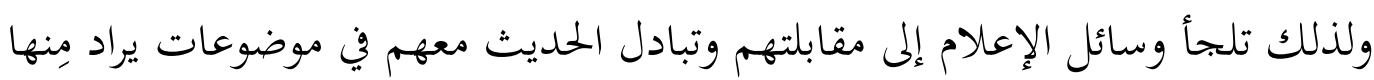

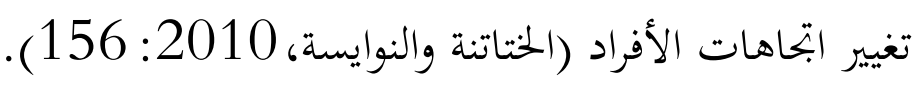
وقد أضاف عبد السلام وآخرون (2002) على ما سبق عامل آخر هو:

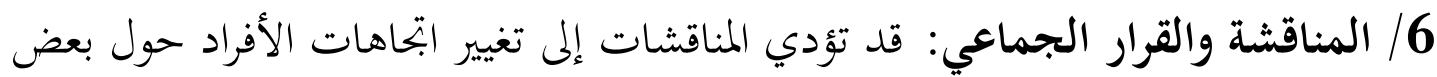

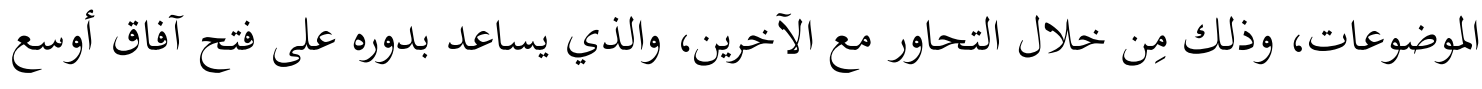

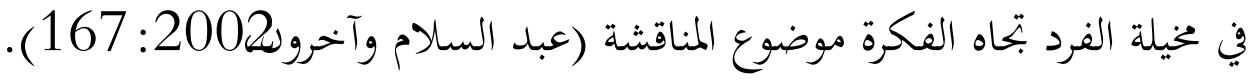

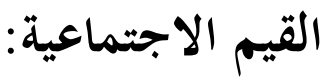

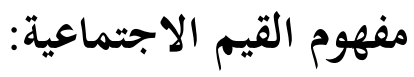


القيم كما يراها علماء الاجتماع هي مقياس أو معيار للانتقاء بين بدائل اجتماعية متاحة أمام الشخص في الموقف الاجتماعي، ويعني المعيار وجود مقياس يضاهي به الأفراد فاعلية الأشياء

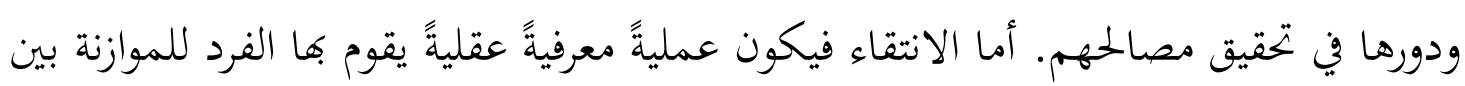

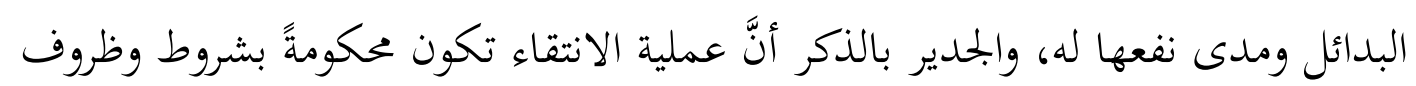
اجتماعية، ويكون مفهوم البدائل هو بحموعة الوسائل والأهداف التي تتجه نحو مصالحهم المتعددة. (عبد السلام وآخرون، 2002: 182). و تعد القيم اهتماهًا أو اختيارًا أو تفضيلًا

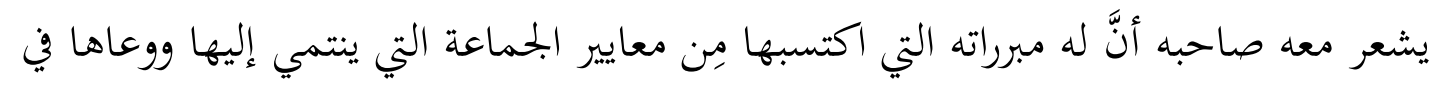
محيط خبراته الاجتماعية؛ نتيجة عملية الثواب والعقاب والتوحد مع الغير. فالمفهوم الاجتماعي للقيم إذن مقتصر على تلك الأنواع مِن السلوك التفضيلي القائم على مفهوم

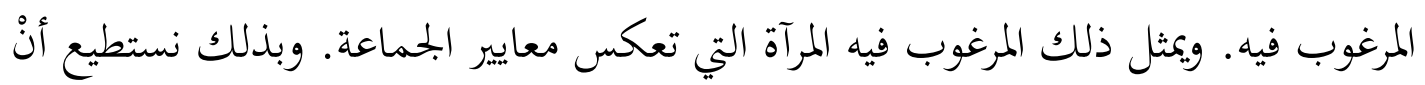

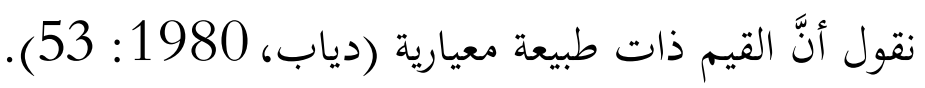

أهمية القيم الاجتماعية: تكمن أهمية القيم الاجتماعية في الدور الذي تشغله في كافة جوانب الحياة الاجتماعية في

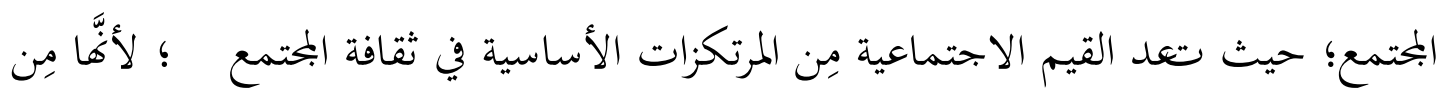

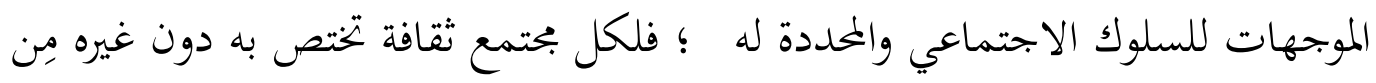
المجتمعات الأخرى، تلك الثقافة المخاصة بما تحمله مِن قيم اجتماعية هي التي ترسم تصرفات

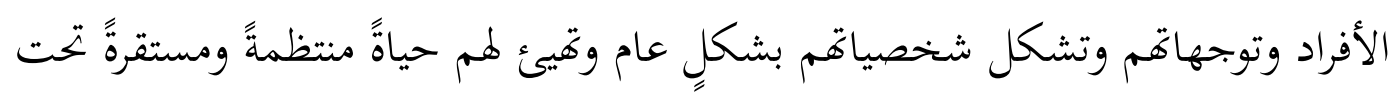

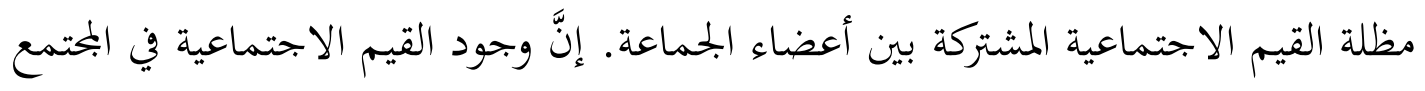
يعد أمرًا حتميًّا، وإلا سوف تكون الحياة الاجتماعية مستحيلةً، ولن يستطيع النظام الاجتماعي الاستمرار في أداء وظائفه وتحقيق رغبات وأهداف الجماعة، كما أنَّا الأفراد

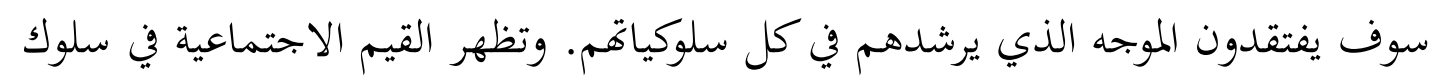

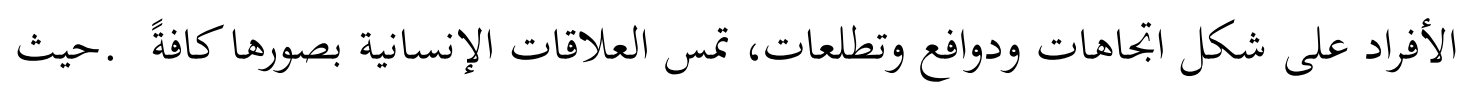

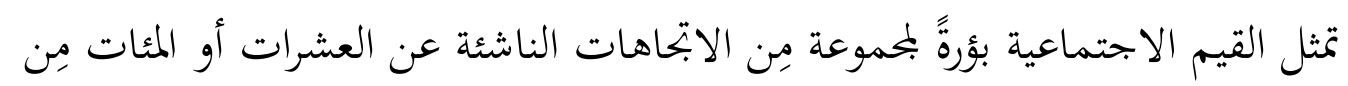

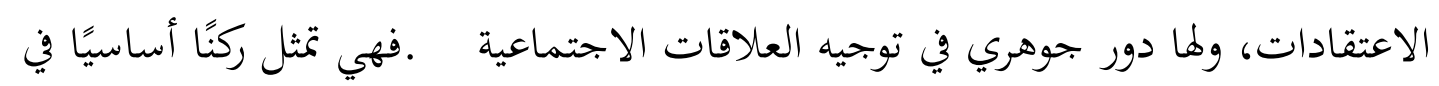
تكوين هذه العلاقات وتحدد طبيعة التفاعل بين الأفراد، وعن طريقها يتم قياس وتقدير 
مواقفهم، ثم التبؤ بسلوكهم وبذلك تساهم القيم الاجتماعية في ربط أجزاء البناء

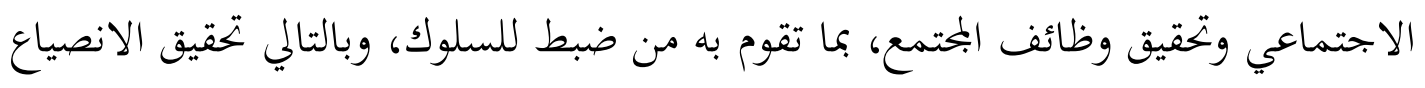

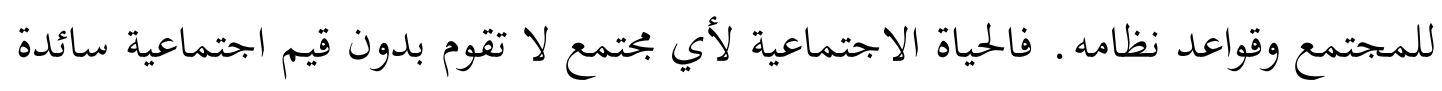

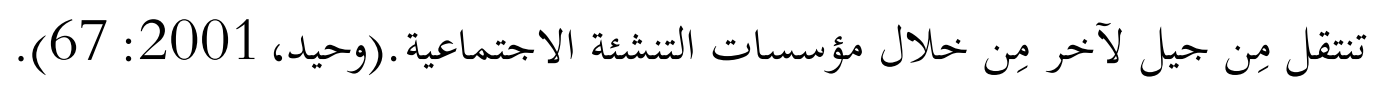

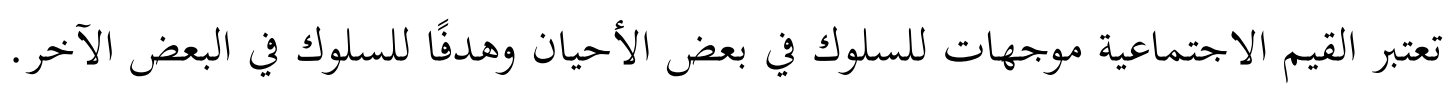

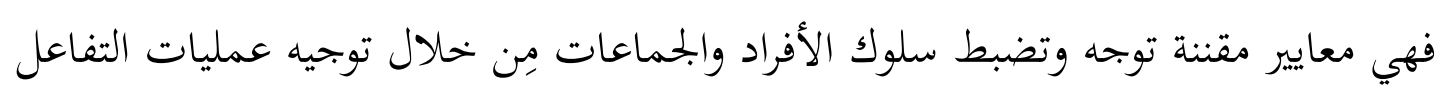
الاجتماعي بين الأفراد في المختمع الواحد، وبين الجماعة والجماعاعات الأخرى؛ لألَّنَ القيم

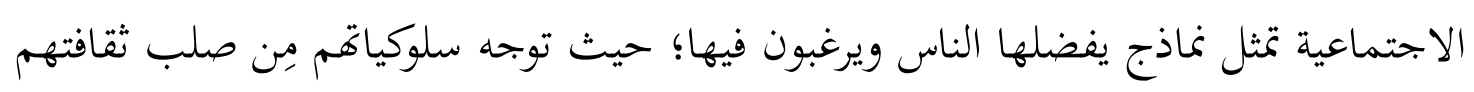

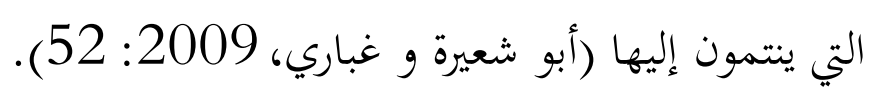

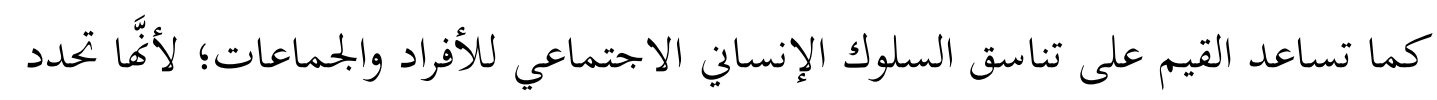

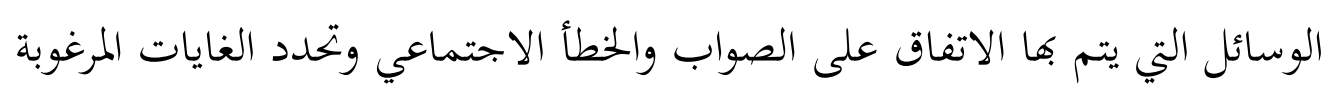

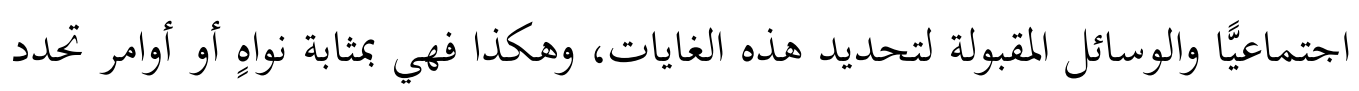

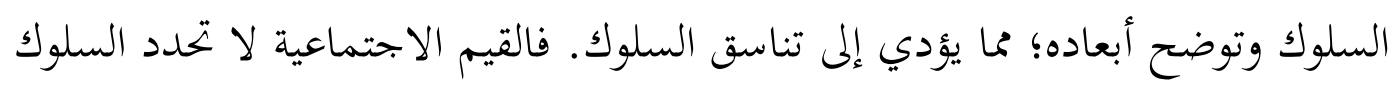

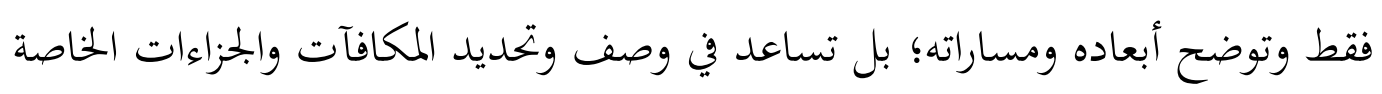

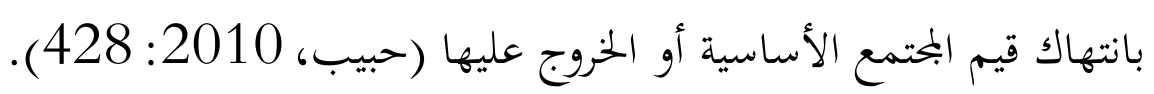

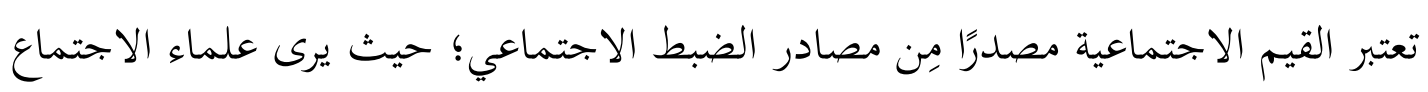

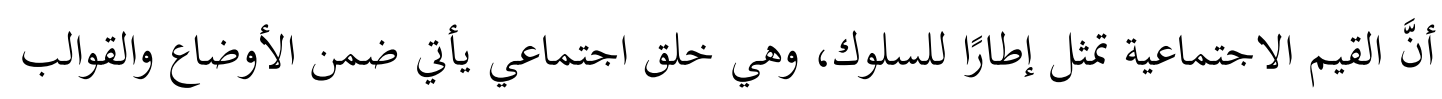

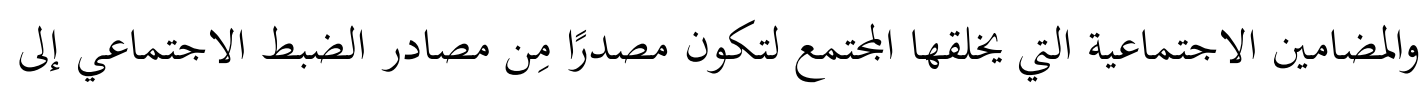

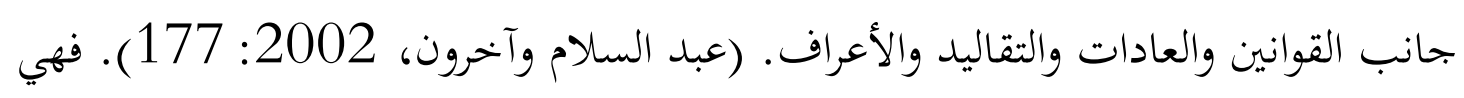

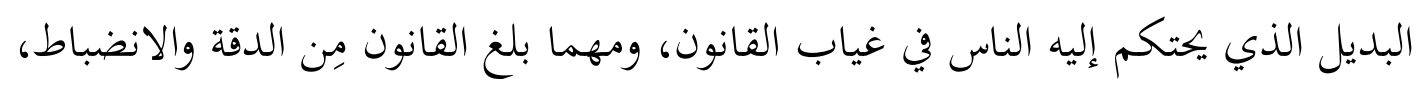

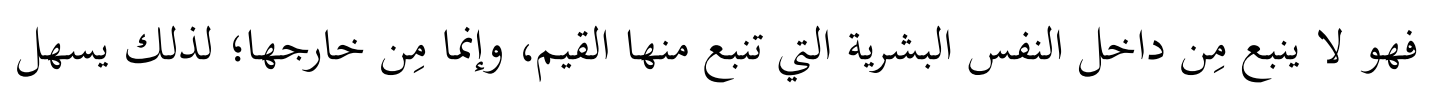

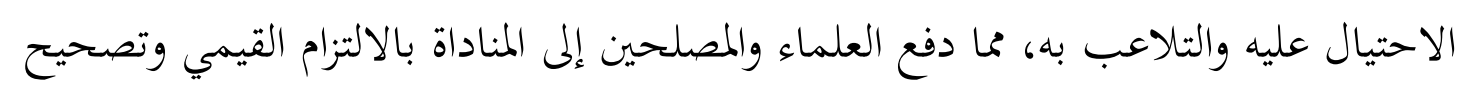

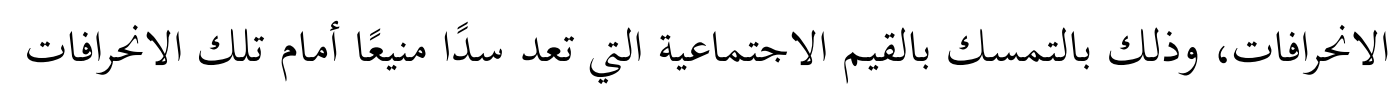
(أبو شعيرة وغباري، 2009: 53 (53). 
وقد أضاف الزيود أنَّ للقيم الاجتماعية أهميةً بالنسبة للفرد والمختمع؛ حيث تعمل على بناء

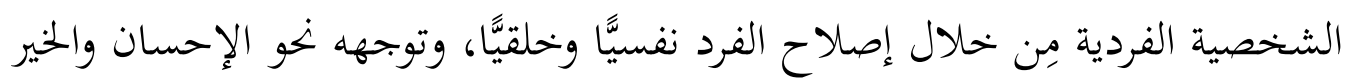

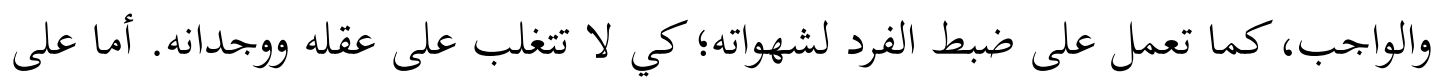

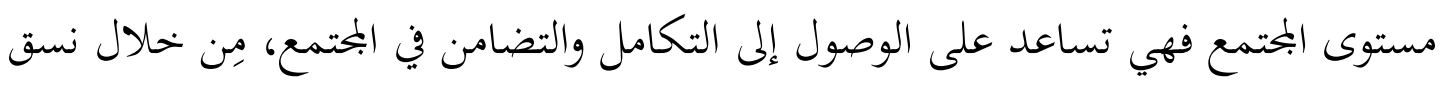

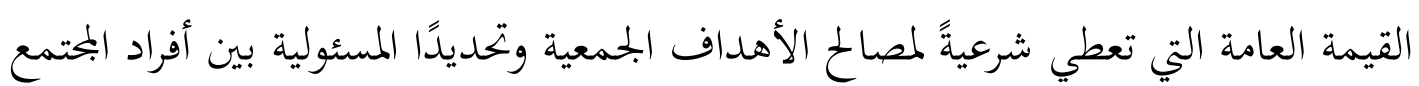
(الزيود، 2011: 28)

كما يرى أبو شعيرة وغباريأنَّ للقيم وظيفتين أساسيتين؛ هما:

1/ ربط العناصر الثقافية بنسيج محكم وربط الثقافات الفرعية في ثقافة واحدة. إنَّ هذه وعيد

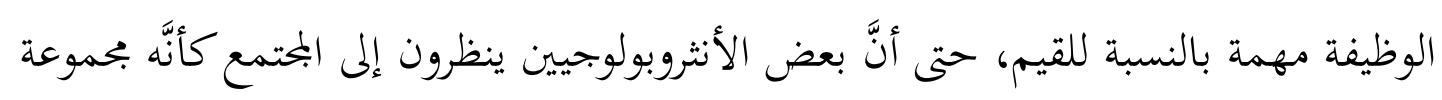
مِن الناس يربطهم في نسيج واحد ونظام مِن القيم. 2/ تحديد أهداف الناس، وبذا تعطي الحياة لديهم شيئًا مِن المعنى، فبدل فئن أنْ يدركوا أعمالهم

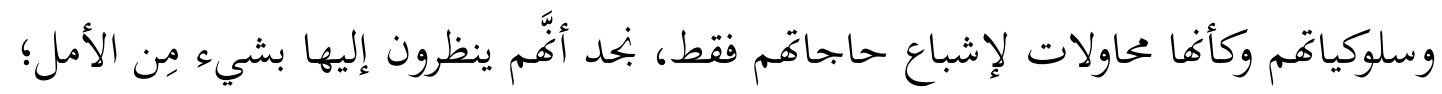

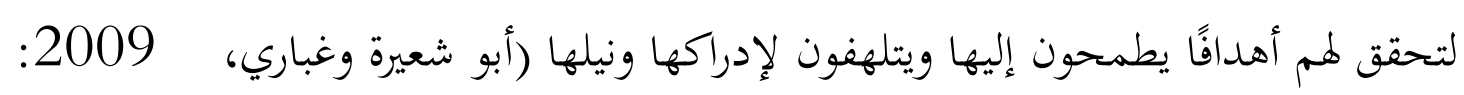

\section{مكونات القيم الاجتماعية:}

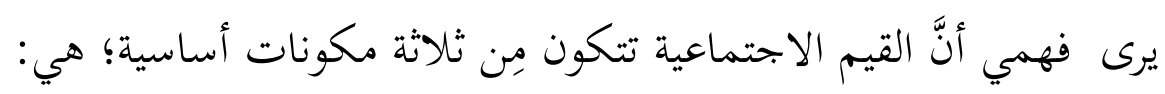

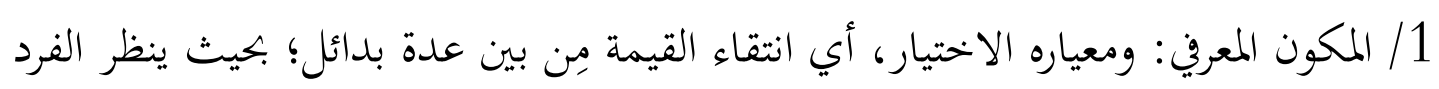
نظرةً كاملةً في عواقب انتقاء كل بديل ويتحمل مسئولية انتقائه.

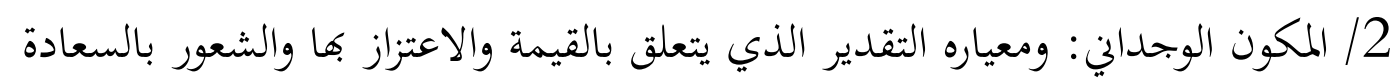
لاختبارها والرغبة في إعلائها على الملأ.

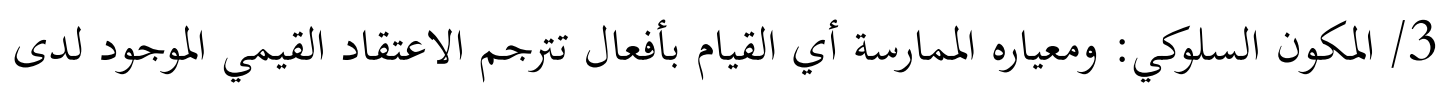
الفرد (فهمي، 1999: 93) ويضيف اليماني وآخرونأنَّ لكل مكون مِن مكونات القيمة الاجتماعية خطوات متتاليةً يتم

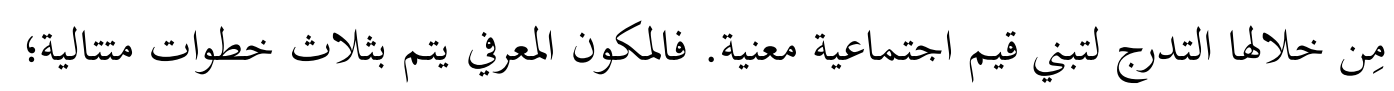

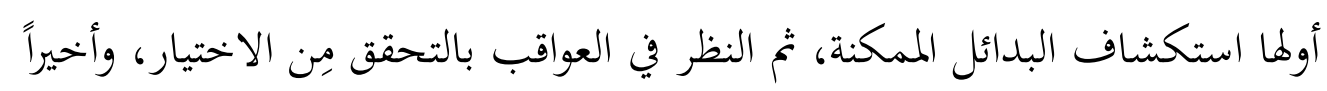


الاختيار. أما المكون الوجداني يتم بخطوتين؛ هما: الشعور بالسعادة لاختبار القيمة، ثم إعلان

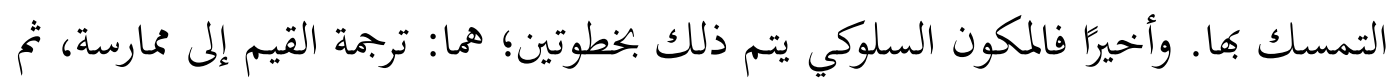
بناء نمط قيمي اجتماعي (اليماني وآخرون، 2011: 42). وقد عبر عماد عن ذلك بقوله تنطوي القيم الاجتماعية على ثلاثة عناصر أساسية؛ هي:

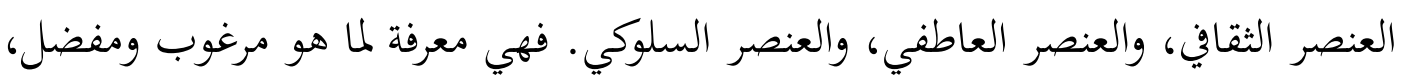

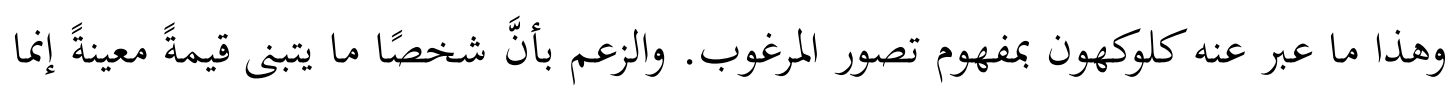
يعني أنَّه يعرف الطريق الصحيح للسلوك الذي ينبغي اتباعه مِن أجل تحقيق هذه القيمة.

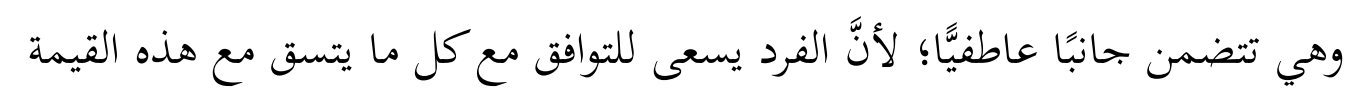

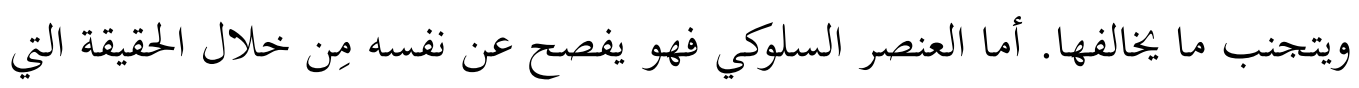
مؤداها أنَّ القيم هي متغيرات وسيطة تحفز على القيام بسلوك معين حين تستثار (عماد، (150:2006

\section{خصائص القيم الاجتماعية:}

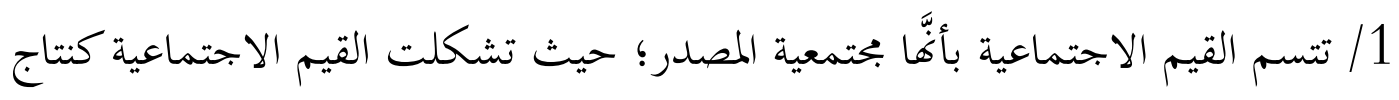

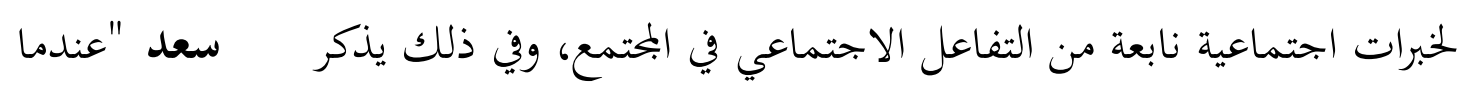

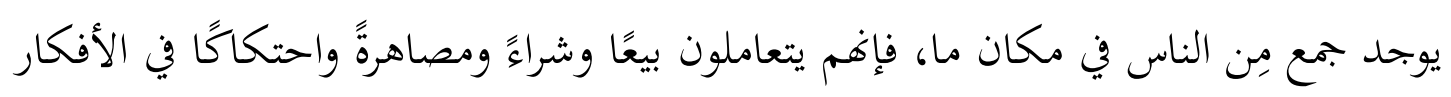

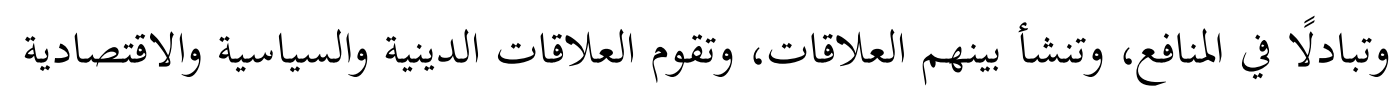

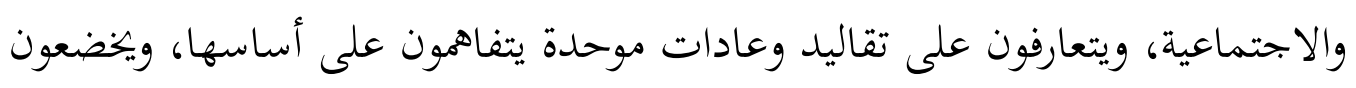

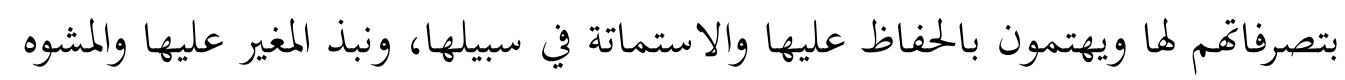
لأنماطها، ويظهر أثر ذلك كله في سلوك الأفراد باعتبارهم أعضاء في الجماعة التي ينتمون

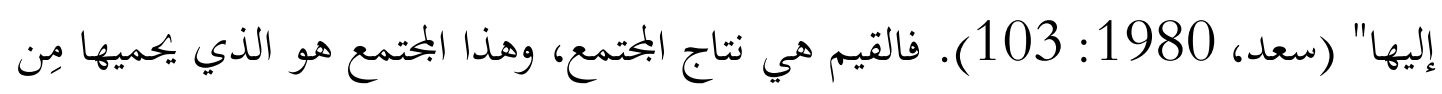

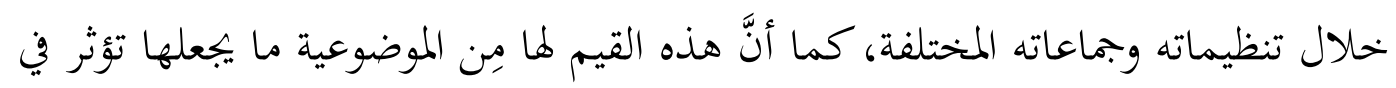

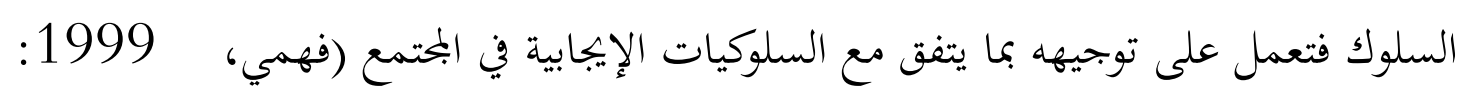
.(100 2/ تتسم القيم الاجتماعية بأََّا رمزية لأكَّا موجهات ومحددات للسلوك، كما يفسر السلوك في

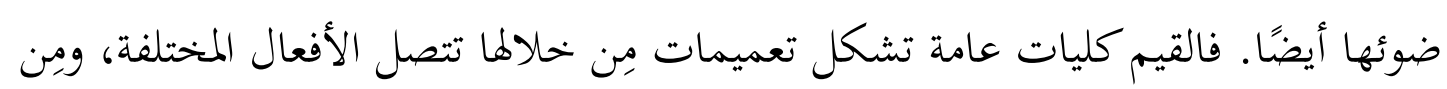


خلالها يمكن فهم فعل معاني الأفعال؛ حيث تحدد أساليب السلوك وتضع المعايير اللازمة له. و

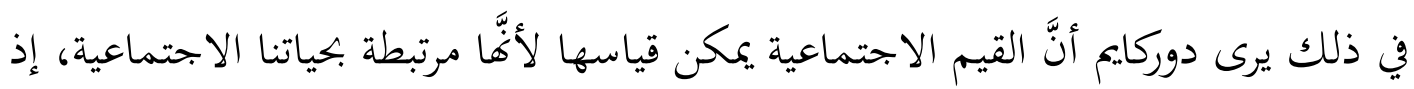

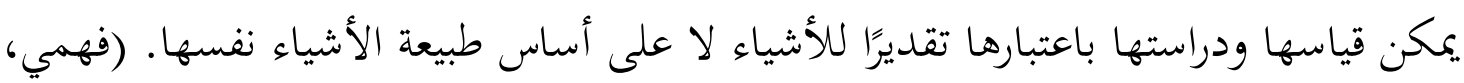

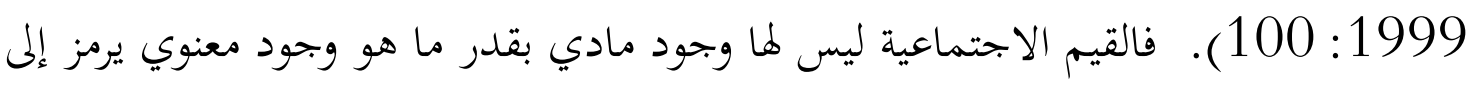
معنى معين.

3/ تتسم القيم الاجتماعية بأغَّا معيارية، فهي بمثابة معيار لإصدار الأحكام تقيس وتقيم وتفسر

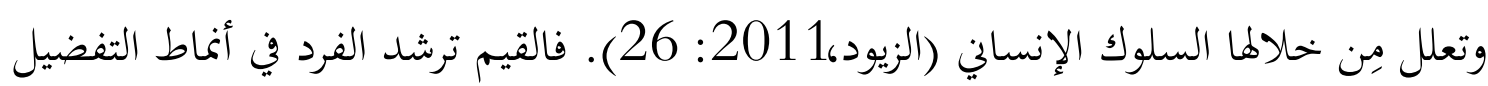

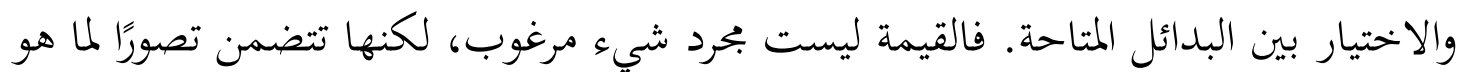
مرغوب. وهذا يعني تفضيلاً لنمط سلوكي في مواجهة نمط آخر كنتاج لعملية مقارنة بينهما.

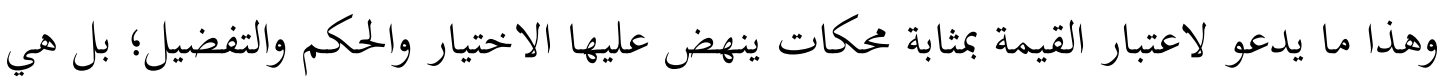

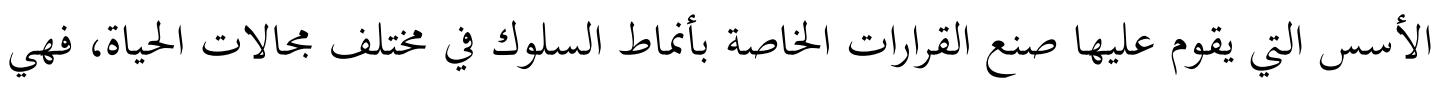

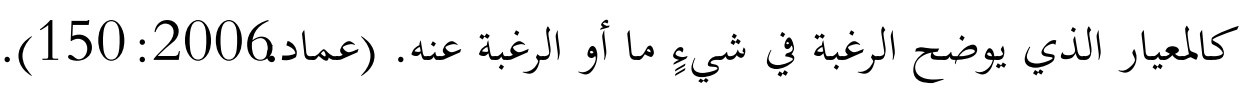

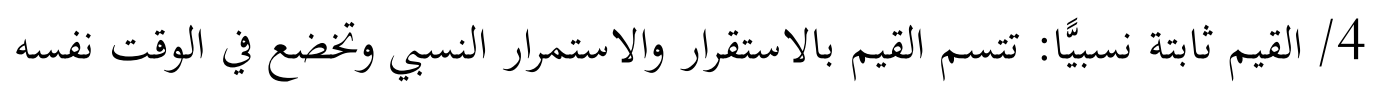

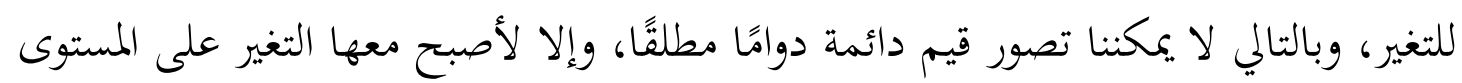

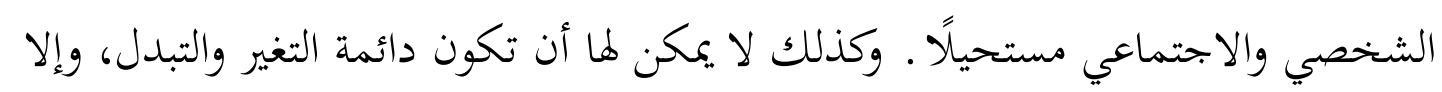

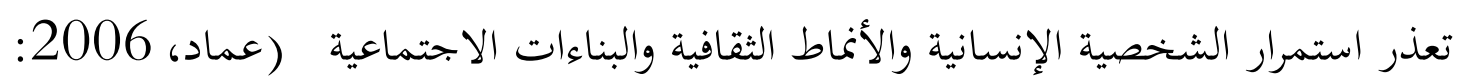

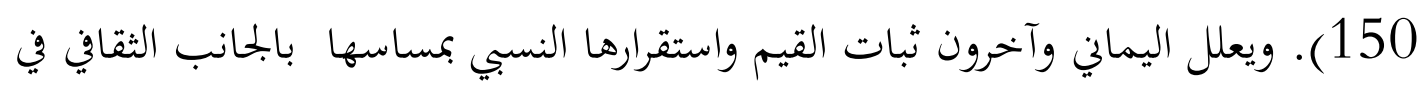
المجتمع الذي يصعب تغييره لحساسية هذا الجحانب مِن الثقافة ولقداسته في نفوس الأفراد،

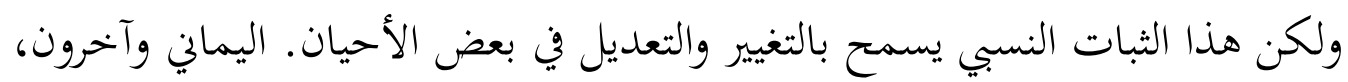
(60 : (2011)

5/ تتسم القيم الاجتماعية بالعمومية، ولا يمكن أنْ تعبر عن بحربة مفردة أو موقف مفرد،

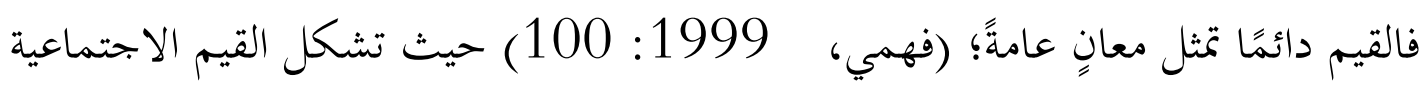

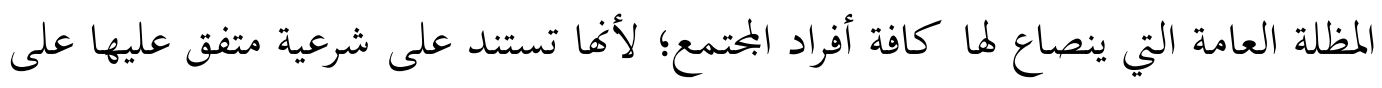

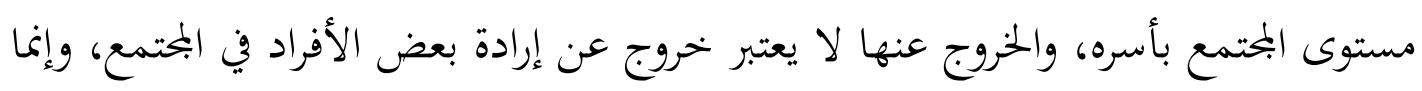
خروج على المختمع بأكمله. 
6/ أغَّاّا متعلَّمة: أي أَََّّا مكتسَبة مِن خلال البيئة وليست وراثيةً، بمعنى أنَّهَ يتم تعلمها

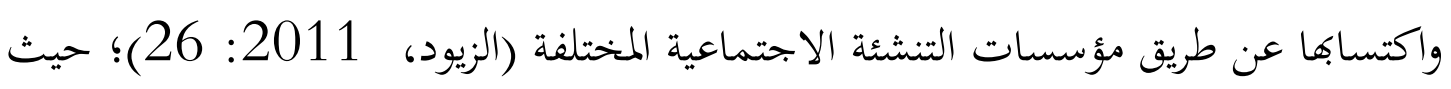

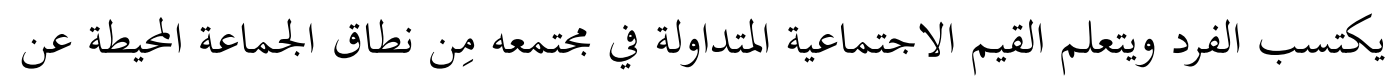
طريق التنشئة الاجتماعية، حيث تتفاعل مؤسسات التنشئة الاجتماعية مع بعضها لترسم معالم الشخصية وتكون القيم الاجتماعية لدى الفرد واتجاهه نحوها. (اليماني وآخرون، . 60 :2011

7/ أنَّا تمتلك صفة الضدية، فلكل قيمة ضدها مما يجعل لها قطبًا إيجابيَّا وآخر سلبيَّا،

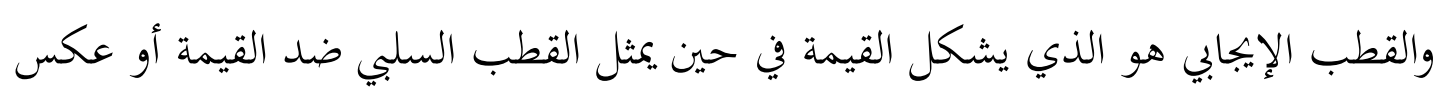

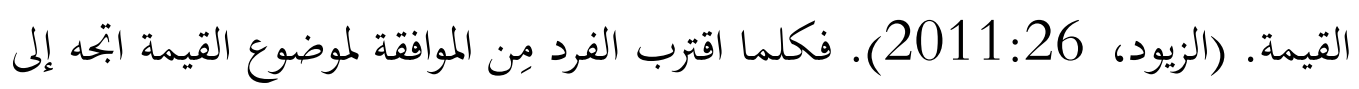
القطب الإيجابي، أما إذا رفض موضوع القيمة ولم يوافق عليه فإنه يتجه إلى القطب السبلي.

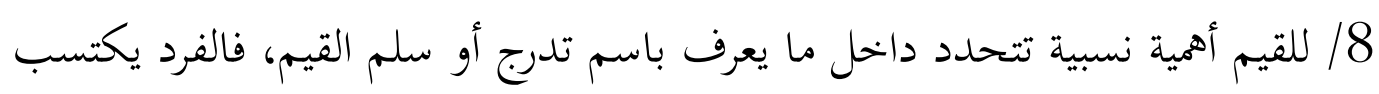

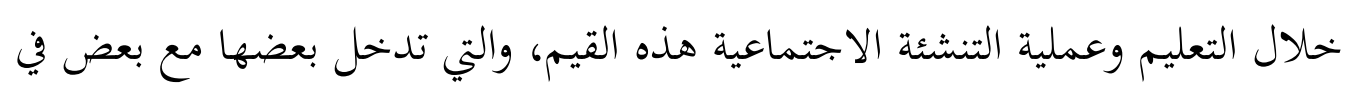

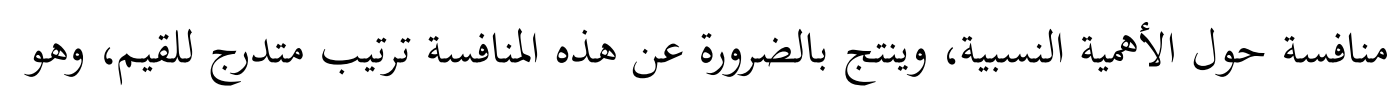
يخضع للتغير كلما استجدت خبرات استدعت إحداث هذا التغير. لذلك فإنَّ دراسة سلم القيم إنما تتم في أضواء المواقف الاجتماعية والتحولات الثقافية والمادية التي تحدث في البحتمع.

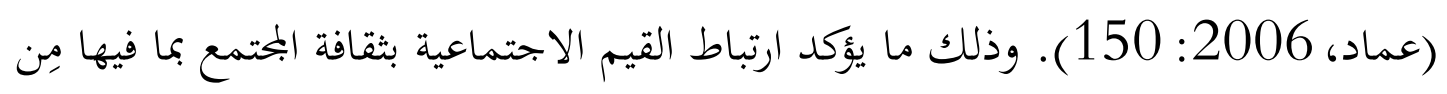
ظروف اجتماعية واقتصادية فهي التي تشكل القيم الاجتماعية؛ لذلك نجد أنَّ هناك نسبيةً للقيم الاجتماعية سواء مِن حيث المكان أو الزمان.

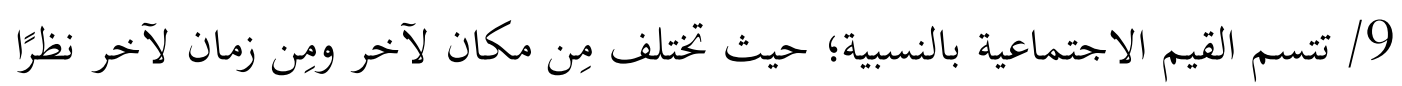
لارتباطها وتأثرها بمختلف الأوضاع الاقتصادية والاجتماعية، فقد تختلف مِن إقليم لآخر داخل البحتمع الواحد، وكذلك باختلاف الطبقات، والوظيفة والمركز الاجتماعي والمستوى بلون التعليمي ( السيف،1997: 1950 185).

اكتساب القيم الاجتماعية:

تمثل عملية التنشئة الاجتماعية في حقيقتها عملية تعليم وتربية، تتم مِن خلالها عملية التفاعل

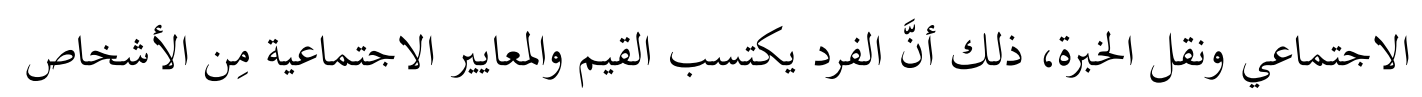


المهمين في حياته فضلاً عن الثقافة العامة التي يعيش فيها. لذلك فإنَّ غالبية الأفراد يتأثرون

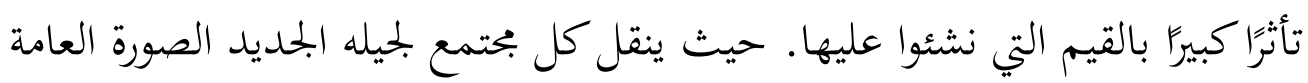

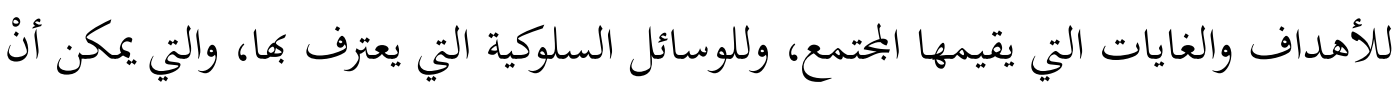
يستعملها كل فرد مِن أفراده؛ لكي يكقق تلك الأهداف، ويصل إلى تلك الغايات، وهذا يعني أنَّ عملية التنشئة الاجتماعية وسيلة المحتمع، لنقل القيم السائدة للأفراد الجحدد مِن فين خلال مختلف مؤسسات التنشئة الاجتماعية. (وحيد، 2001: 68).

مؤسسات التنشئة الاجتماعية:

$$
\text { أولاً: الأسرة: - مؤسنات }
$$

تعد الأسرة مِن أهم الجماعات الإنسانية وأعظمها تأثيرًا في حياة الأفراد فهي الوحدة البنائية

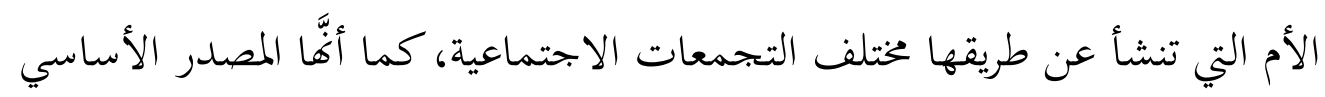

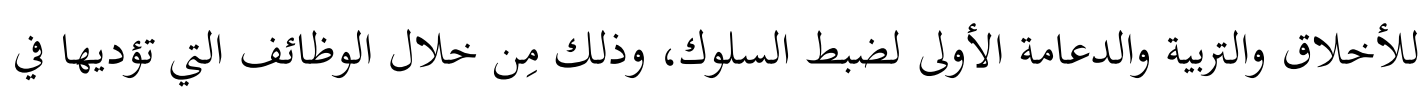

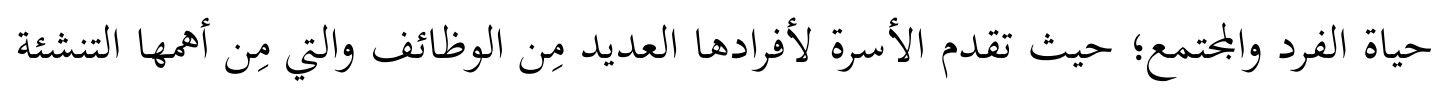

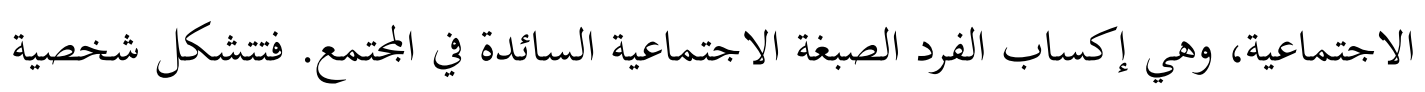

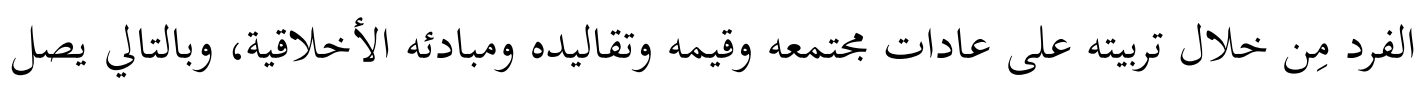

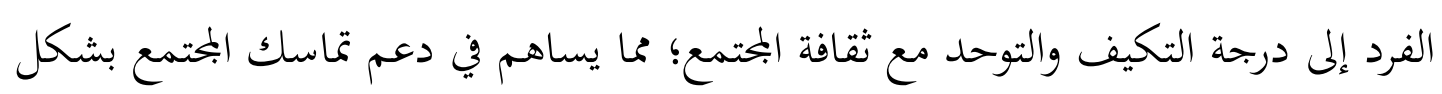

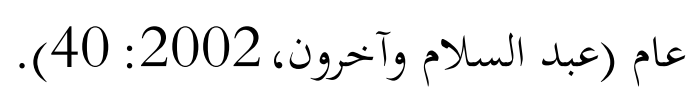

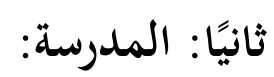

المدرسة هي المؤسسة الاجتماعية التي تقوم بوظائف التربية ونقل وتوفير الظروف المناسبة للنمو الجسدي والانفعالي والاجتماعي ؛حيث تقوم بدور فعال في توجيه سلوك الفرد وتقويم

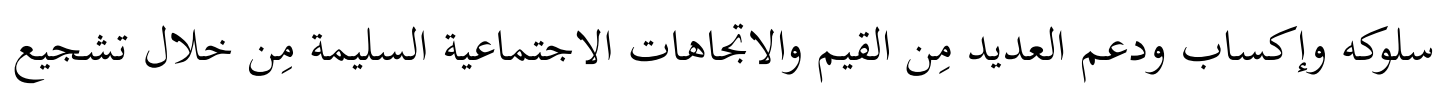

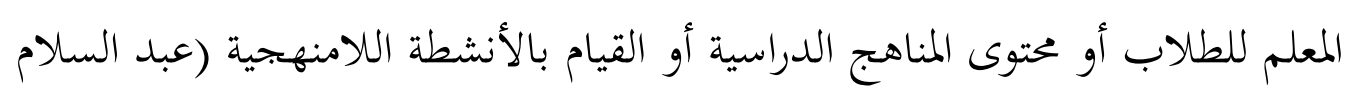

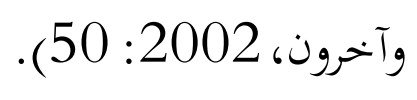

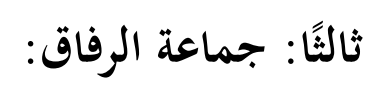

تعد جماعة الرفاق مِن أهم مؤسسات التنشئة الاجتماعية على الرغم مِن كوغا غير مؤسسية إلا

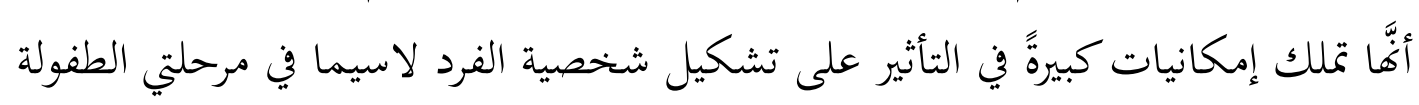


والمراهقة، فالتفاعل الاجتماعي داخل الجماعة يعد مِن المؤثرات الهامة التي تتؤثر على تشكيل

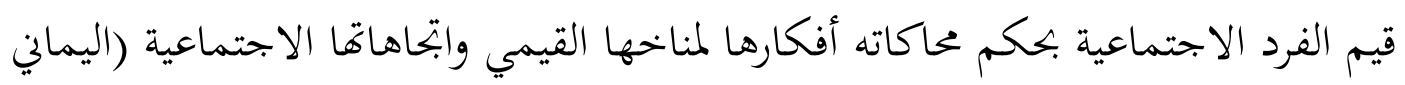

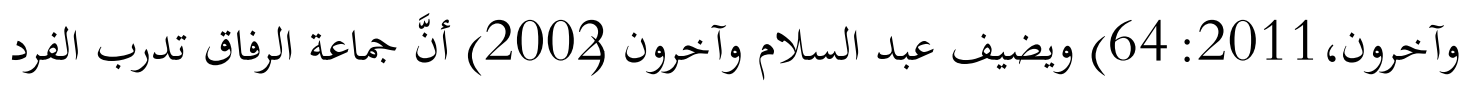
على تحمل المسئولية والاستقلالية كما تساعده على إشباع حاجة الانتماء. كما يتوقف مدى

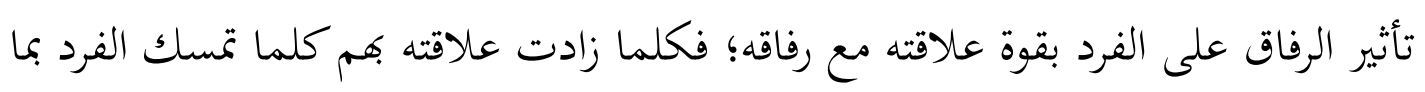

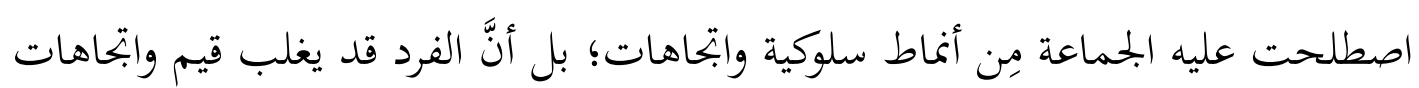

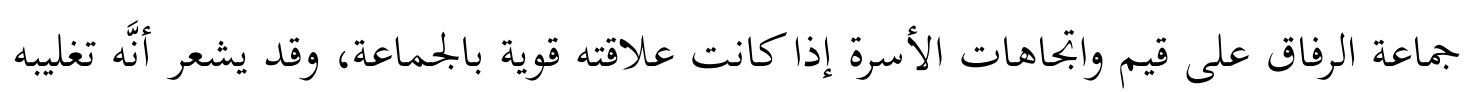
لابحاهات جماعته يعزز استقلاليته ويدعم سماته الشخصية وابكاه

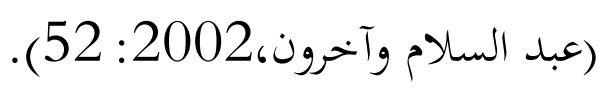

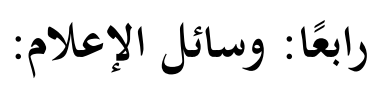

نظرًا لما تتميز به وسائل الإعلام بكافة أنواعها مِن أهمية كبيرة؛ حيث تحتل جزيًا كبيرًا مِن

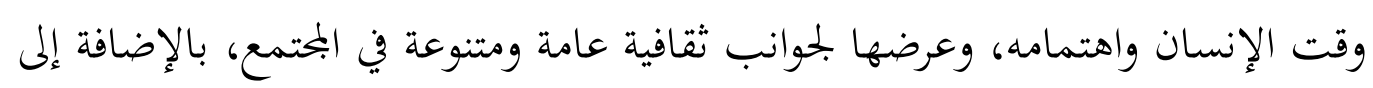

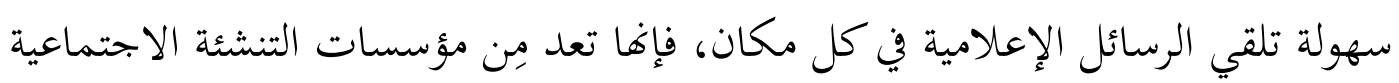

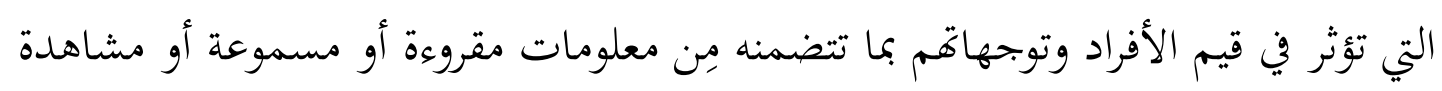

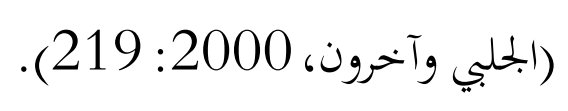

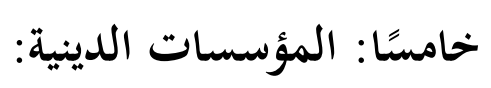

للمؤسسات الدينية أهميتها في عملية التنشئة الاجتماعية وغرس القيم الاجتماعية وتوجيهها في نقوس الأفراد؛ حيث تتمتع المؤسسات الدينية في البحتمع بهالة مِن القدسية والتقدير

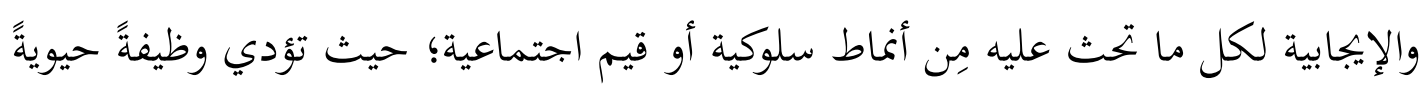

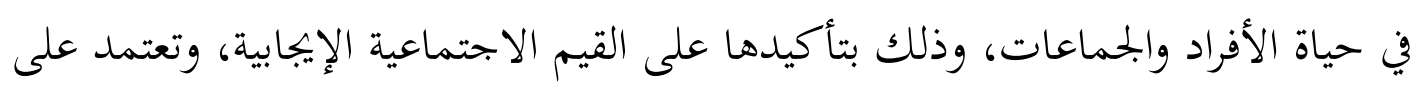

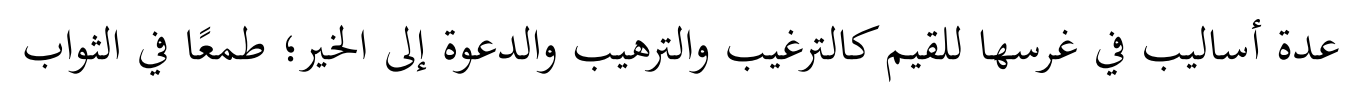
والابتعاد عن الشر، وبتنبًا للعقوبة وعرض النماذج السلوكية المثالية والإرشاد العلمي (اليماني وآخرون، 2011 201 64). 
تعد قيمة تحمل المسؤولية مِن القيم الاجتماعية التي تنم عن شخصية متزنة في ذاتما ومتفاعلة

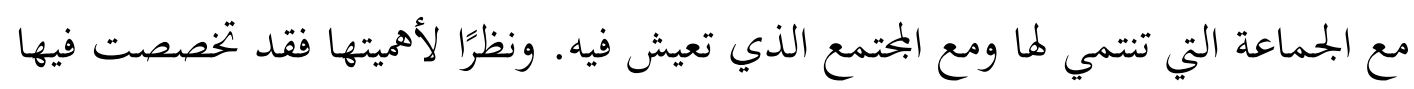

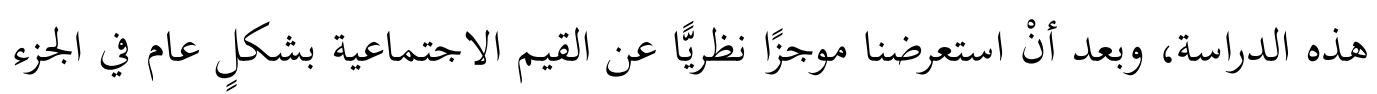

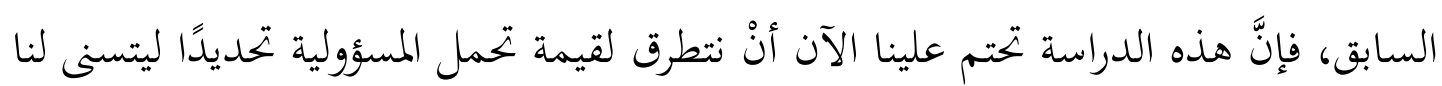

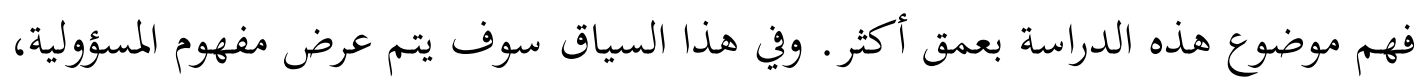

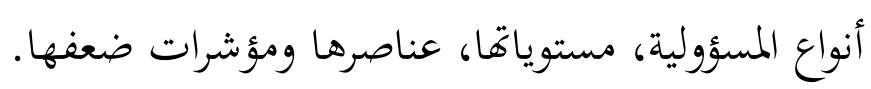

\section{مفهوم قيمة تحمل المسؤولية:} مفهوم قيمة تحمل المسؤولية مثله مثل أي مفهوم نظري آخر تعددت فيه الصياغات بالرغم مِن اتفاق الباحثين على خطوطه العامة؛ فقد وضحها جاكيوز بأهَّا

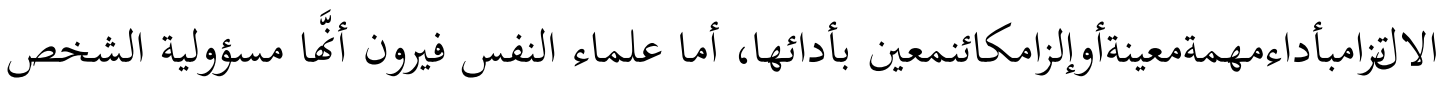

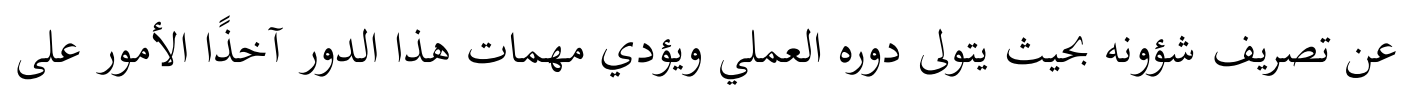

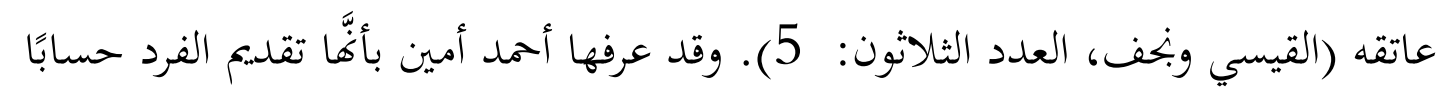

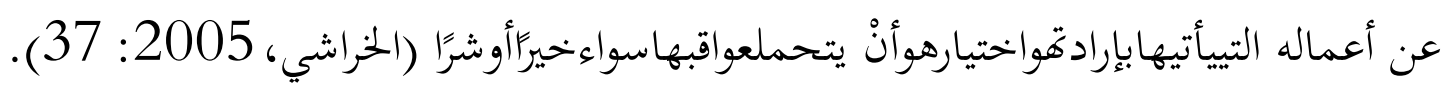

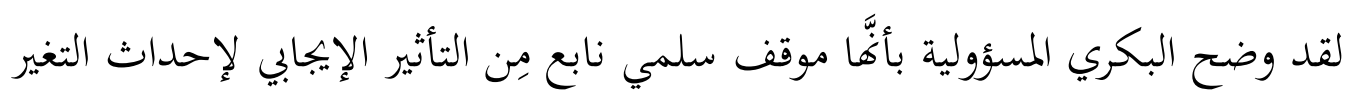

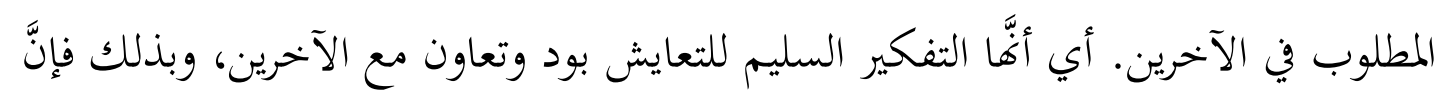

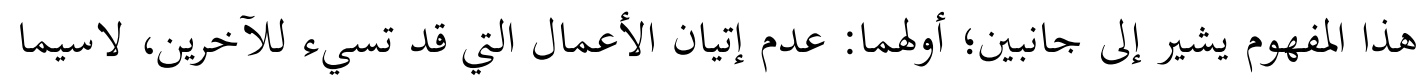

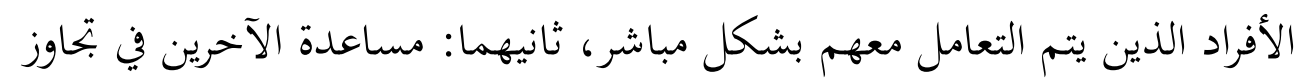

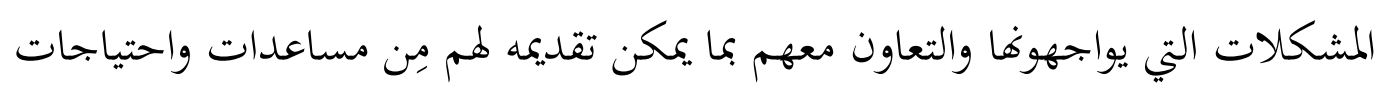
مختلفة (البكري، 2009: 26). كما يشير مفهوم المسؤولية إلى المسؤولية الفردية عن يون الجماعة، فهي مسؤولية ذاتية وأخلاقية؛ مسؤولية فيها مِن المراقبة الداخلية والمحاسبة الذاتية.

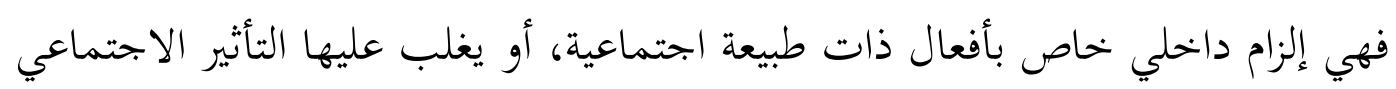

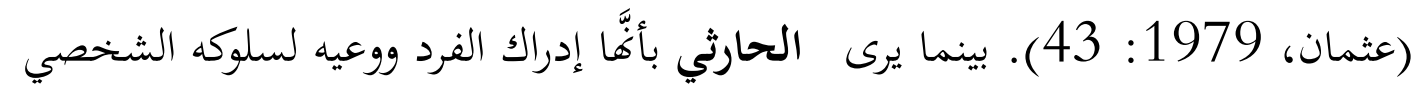

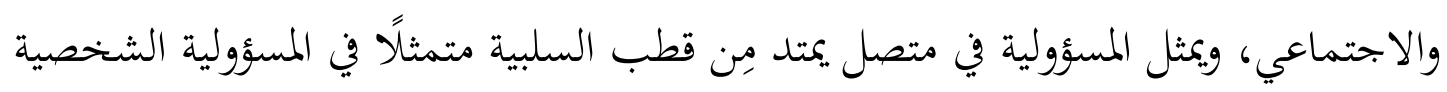
الذاتية إلى أقصى درجات الإيجابية في القطب؛ حيث تزداد المسؤولية بتحاه البحتمع والعالم، 
وذلك ما يدلل على أنَّ المسؤولية لا تنعدم تمامًا؛ بل أََّاّا موجودة بنسب متدرجة

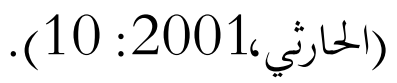

ووِن خلال استعراض المفاهيم السابقة لقيمة المسؤولية نستطيع أنْ نوضح مفهوم قيمة تحمل

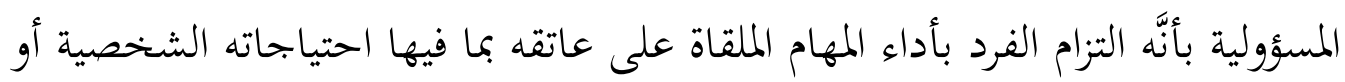
احتياجات الجماعة التي ينتمي إليها؛ بحيث يصبح مِن الأعضاء الفعالين في المجتمع.

أنواع المسؤولية:

للمسؤولية ثلاثة أنواع رئيسة تختلف باختلاف المصدر والسلطة التي تستمد منها إلزاميتها؛ وهي: 1/ المسؤولية الدينية: ويقصد بها التزام الفرد بالأوامر الدينية والنواهي، وقبوله لما يترتب عليها

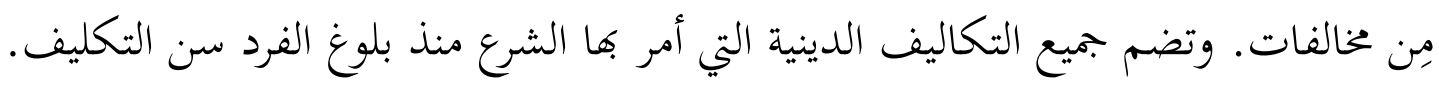
2/ المسؤولية الاجتماعية: وهي التزام الفرد في أفعاله بما يتناسب مع ثنافة المجتمع، وتقبله للعقوبات التي قد تقع عليه في حال مخالفته لها. ويستمد هذا النوع مِن المسؤولية قوته مِن القدسية التي يرسمها النظام الاجتماعي لنفسه. 3/ المسؤولية الأخلاقية أو الأدبية: وتعني التزام الفرد بمراقبة أفعاله وسلوكه بموجب ما يمليه

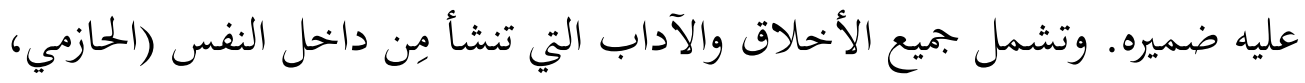
(53) 1428

وبطبيعة الحال فإنَّ أنواع المسؤولية قد تتداخل مع بعضها البعض وكل منها يرتبط بالآخر؛

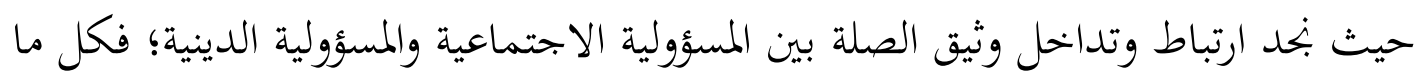
هو اجتماعي قد يشمل الجوانب الدينية، وكل ما هو اجتماعي قد يتكون في الأساس مِن

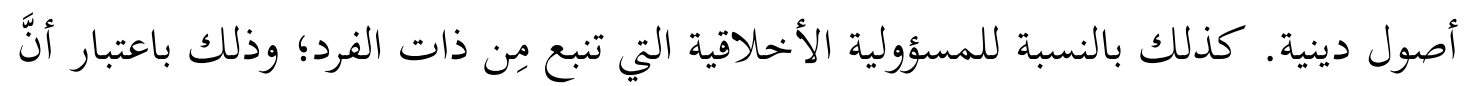

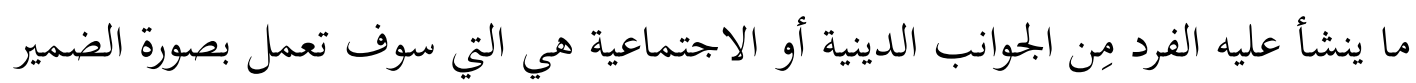

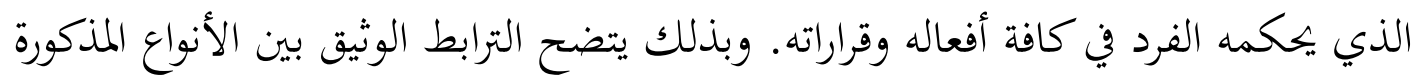

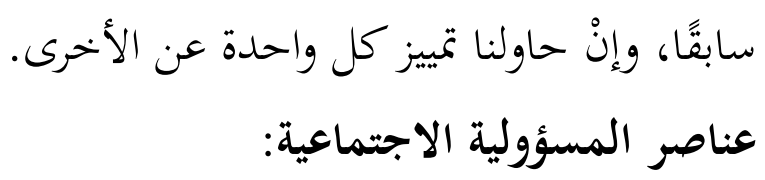
تنقسم عناصر المسؤولية إلى ثلاثة أقسام تتمثل في الآتي: 
1/ الاهتمام: ويرتبط بالجانب الوجداني أي الارتباط العاطفي بالجماعة التي ينتمي إليها

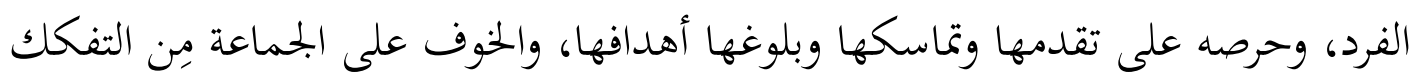
أو الضعف. وللاهتمام أربعة مستويات؛ الأول الانفعال مع الجماعة ؛ أي أنْ يساير الفرد

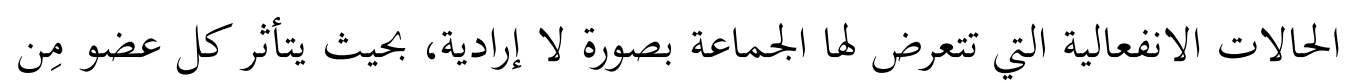
أعضائها بما يجري في الجماعة كلها دون قصد، فالفرد عند هذا المستوى مساير انفعاليَّا للجماعة بصورة آلية . الثاني الانفعال بالجماعة، وهو مستوى أرقى مِن السابق والمقصود به به بهائ التعاطف مع الجماعة ، ويختلف عن المستوى السابق في أنَّ الفرد هنا يدرك ذاته أثناء انفعاله

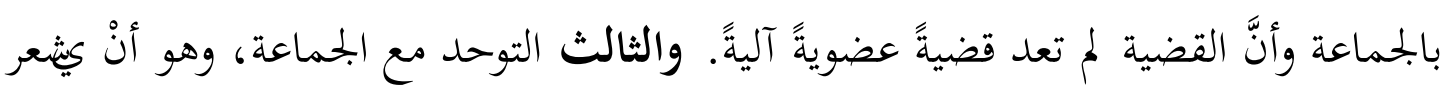

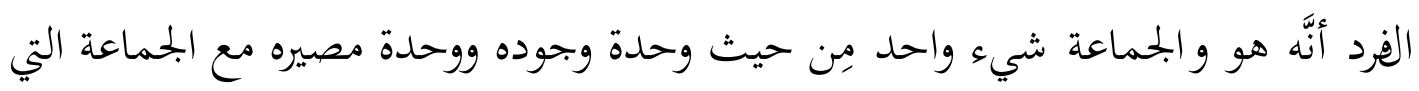

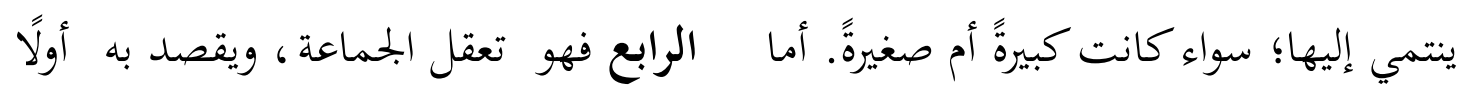

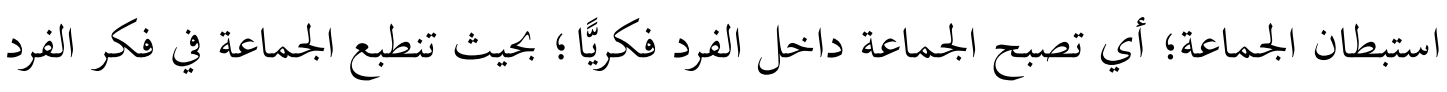

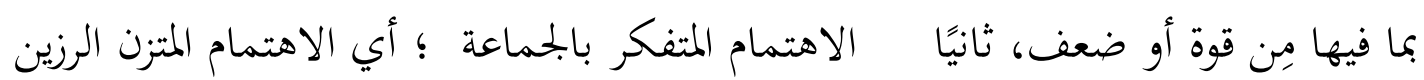
بمشكلات الجماعة ومصيرها والعلاقة ودرجة التناسب بين أنشطتها وأهدافها وسير مؤسساتحا

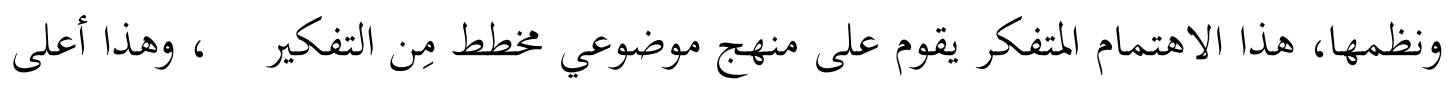
مستويات الاهتمام بالجماعة؛ حيث يجاوز المستوى الوجداني إلى الجانب الفكري.

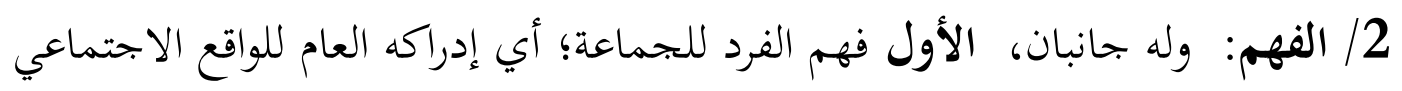

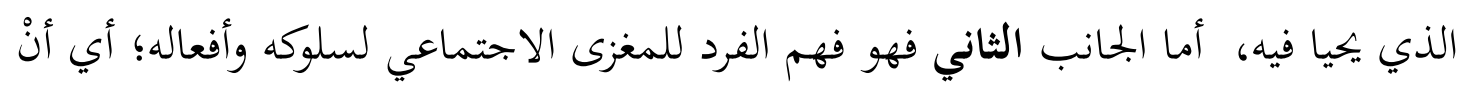

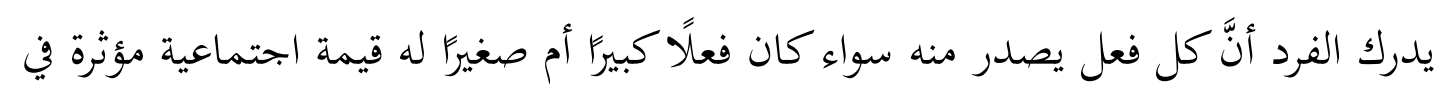
الجماعة. 3/ المشاركة: وهي الترجمة الفعلية للعنصرين السابقين؛ حيث يمثل الاهتمام الجانب الوجداني للفرد ويمثل الفهم الجانب الفكري للفرد، وهاثلاثة جوانب؛ أولها تقبل الفرد للدور الاجتماعي وما يقوم به الفرد مِن سلوك وتوقعات، وهذا التقبل ضروري حتى يشارك الفرد في أنشطة ونها الجماعة، ثانيها المشاركة المنفذة وهي المشاركة التي تتمثل في العمل الفعلي المشترك؛ أي العمل

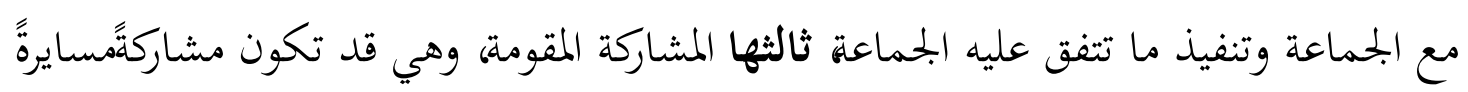

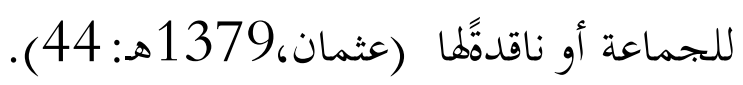




\section{مستويات المسؤولية:}

تتدرج مستويات المسؤولية في حياة الفرد وفق الآتي: 1/ المستوى الفردي (المسؤولية الفردية): وتتضمن مسؤولية الفرد عن نفسه أي عن احتياجاته الشخصية وعن أفعاله التي يقوم بها بإرادته. 2 المستوى الجماعي (المسؤولية الجماعية): وتكمن فيها مسؤولية الجماعة عن لئن أعضائها مِن حيث سلوكهم وأعمالهم وقراراقهم.

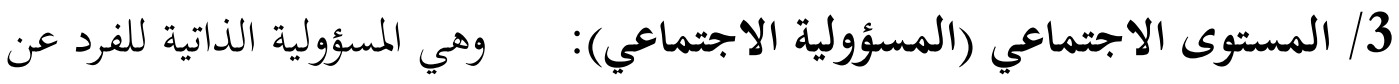
الجماعة. وتتداخل تلك المستويات مع بعضها البعض، وكل منها يؤدي للآخر (الحازمي، (53) 1428 وبطبيعة الحال، فإِنَّ آراء الباحثين قد يكون فيها شيء من الاختلاف، فكما رأينا التقسيم

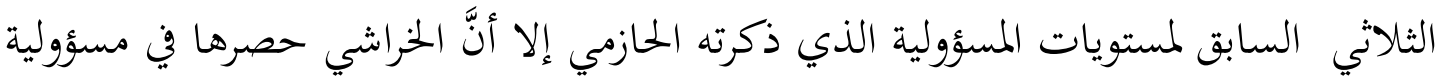
الفرد بحاه نفسه؛ أي كمستوى شخصي، ومسؤولية الفرد بتحاه المختمع كمستوى اجتماعي.

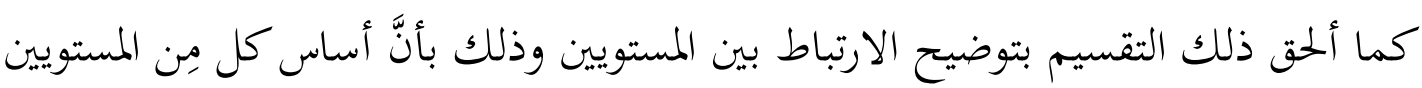
نابع ومكمل للآخر (الخراشي،1425هـ: 49). مؤشرات ضعف المسؤولية:

هناك العديد مِن المؤشرات التي توضح أنَّ هناك اعتلال في المسؤولية لدى الفرد؛ منها:

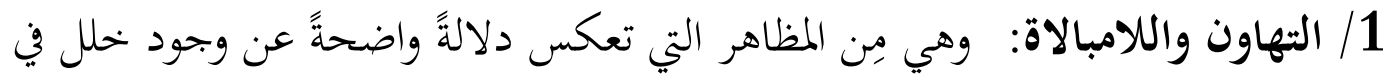

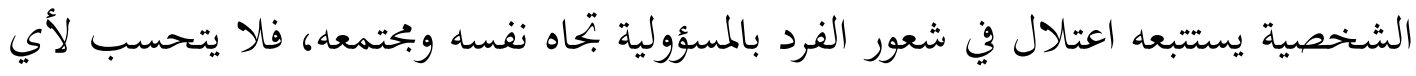
نتيجة قد تحصل تبعًا لأفعاله أو قراراته. 2/ العزلة: وتعني الغياب المعنوي للفرد عن جماعته فقد يكون حاضرًا لكنه غير منسجم مع إسله أفراد الجماعة. 3/ التفكك: وهو أكثر الصور دلالةً على ضعف مشاركة الفرد في أمور جماعته.

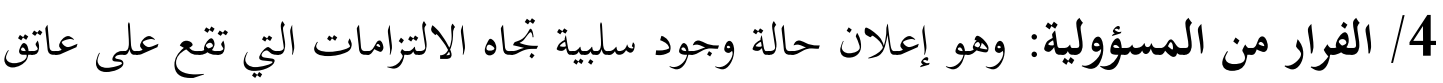

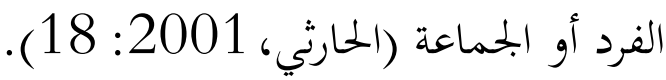




\section{المراجع

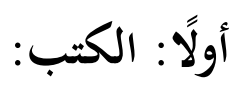

ا - أبو شعيرة، خالد وغباري، ثائر(2009). الثقافة وعناصرها. عمان: مكتبة البحتمع العربي.

r بني جابر، جودة (2011). علم النفس الاجتماعي. عمان: دار الثقافة. r - -البكري، ثامر (2009). التسويق والمسؤولية الاجتماعية. الأردن: دار وائل. ع - الجلبي وآخرون، عبد الرزاق(2000). علم الاجتماع الثقافي. الإسكندرية: دار المعرفة الجامعية.

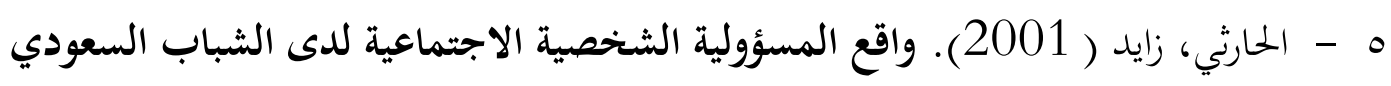

$$
\text { وسبل تنميتها. الرياض: مركز الدراسات والبحوث. }
$$

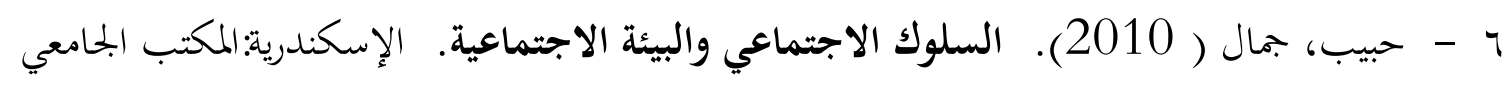
الحديث.

V - الختاتنة، سامي والنوايسة، فاطمة (2010). علم النفس الاجتماعي. الأردن: دار الحامد.

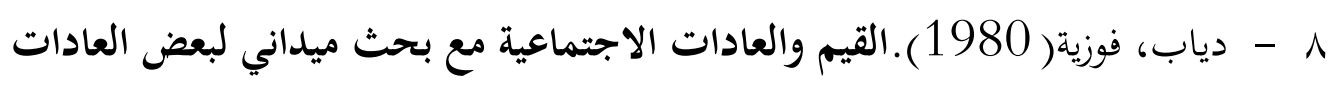
الاجتماعية. بيروت: دار النهضة.

9 - - ربيع، محمد (2011). علم النفس الاجتماعي. عمان: دار المسيرة. • ا - الزيود، ماجد(2011). الشباب والقيم في عالم متغير. الأردن: دار الشروق. 11 ب - السيف، محمد (1418هـ). المدخل إلى دراسة المجتمع السعودي. الرياض: داضئ دار الخريجي. r ا ا -عبد اللا، محمد (2012). علم النفس الاجتماعي. الإسكندرية: دار الوفاء.

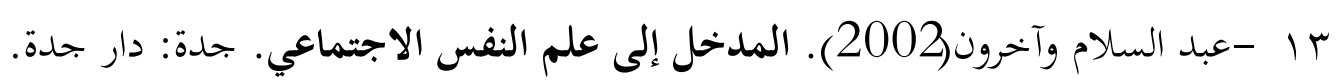
ع ا -عبد الهادي، نبيل(2011). تشكيل السلوك الاجتماعي. عمان: دار اليازوري.

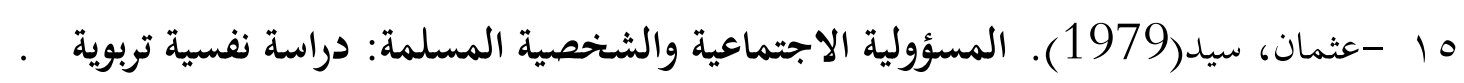
القاهرة: مكتبة الأنجلو المصرية.

17 ا 17 -عماد، عبد الغني( 2006 ). سوسيولوجيا الثقافة: المفاهيم والإشكاليات.. الإسكندرية الحداثة إلى العولمة. بيروت. مركز دراسات الوحدة العربية.

IV - فهمي، نورهان (1999م). القيم الدينية للشباب. الإسكندرية: المكتب الجامعي الحديث.

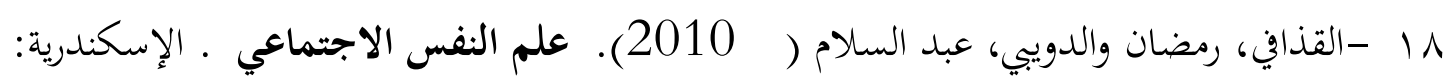

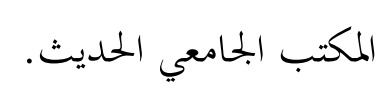

19 19 
• . F - اليماني وآخرون، عبد الكريعا(2011). القيم في الفكر التربوي والإسلامي الأردن: دار غيداء. ثانيًا: الرسائل العلمية: ا لحلحازمي،مرام (1428هـ). موقف طلاب الجامعة مِن بعض القيم التربوية في المجتمع السعودي. رسالة ماجستير غير منشورة. جامعة الملك سعود. الرياض.

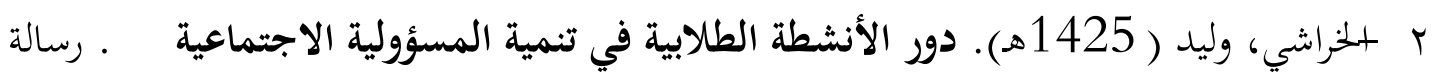

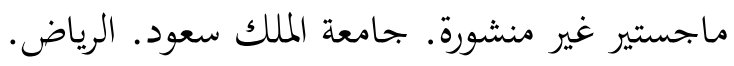

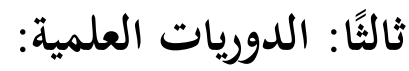
1

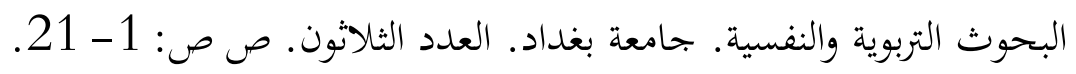

